\title{
Well-being through Song: A Biopsychosocial Examination of Singing in Community Dwelling Older Adults
}

\author{
by
}

Laura Thompson

A thesis submitted to the Faculty of Graduate and Postdoctoral Affairs in partial fulfillment of the requirements for the degree of

Master of Arts

in

Psychology

Carleton University

Ottawa, Ontario

C 2016, Laura Thompson 


\title{
WELL-BEING THROUGH SONG
}

\begin{abstract}
The present study examined changes in well-being over single sessions of group singing as compared to musical (band) and non-musical (bridge club) control group activities. One hundred and eleven older adults $\left(M_{\mathrm{age}}=73\right.$ years, $\left.S D=8.26\right)$ recruited from seniors' recreation centers completed measures of well-being before and after singing $(n=48)$, band $(n=31)$, or card $(n=32)$ activities. Singing demonstrated benefits beyond the other leisure activities, including a trend to increase in positive affect (PA) while control groups significantly decreased, and a unique significant increase in vitality. Past research was extended upon through exploration of mechanisms of the association between singing and well-being. PA was found to mediate the association between singing and social bonding. These findings may provide valuable information about benefits of singing and cost-effective programs to enhance well-being in older adults.
\end{abstract}




\section{WELL-BEING THROUGH SONG}

\section{Acknowledgements}

First and foremost I would like to thank my supervisor Dr. Mary Gick, without her continuous support and guidance this thesis would not have been possible. I would also like to thank my thesis committee, Dr. Patrick Hill, Dr. Karen March, and Dr. Marina Milyavskaya for their valuable feedback. A big thank you to my colleagues and friends, Christine, Cassandra, and Farooq, for their encouragement, advice, and neverending support. To Noelle, for not only commiserating with me, but also cheering me on and making my time at Carleton so much more enjoyable. Thanks is also due to all of the seniors' centers and groups that welcomed me through their doors and allowed this study to be conducted. I would also like to thank AIRS SSHRC MCRI (Advancing Interdisciplinary Research in Singing - a Social Sciences and Humanities Research Council of Canada Major Collaborative Research Initiative) for their financial support. Finally, thank you to my family and my boyfriend Andrew for their endless patience and understanding throughout the completion of this project. 


\section{WELL-BEING THROUGH SONG}

\section{Table of Contents}

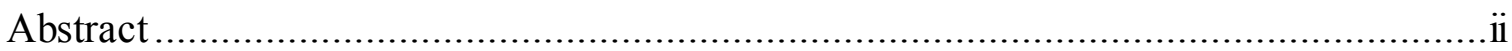

Acknow ledgements .................................................................................

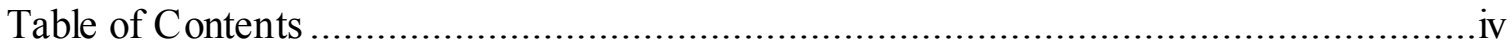

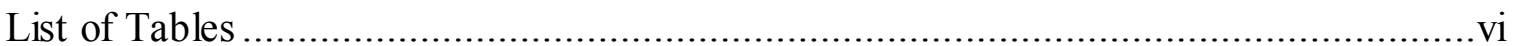

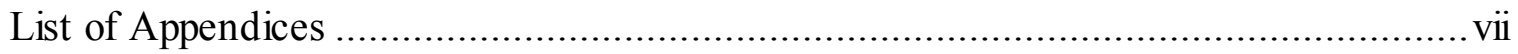

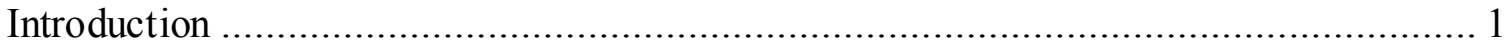

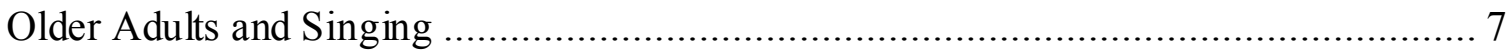

Psychological Benefits .................................................................. 7

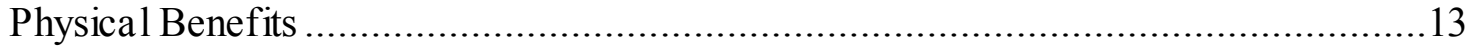

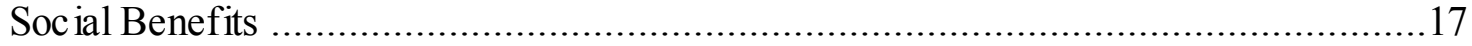

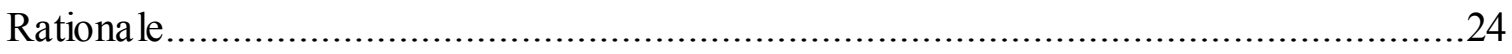

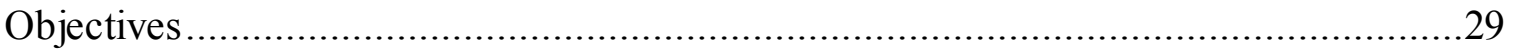

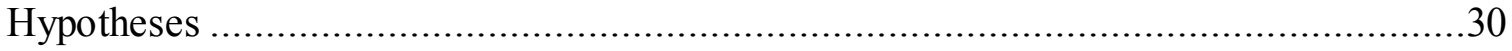

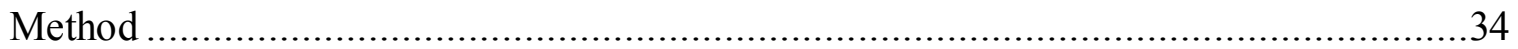

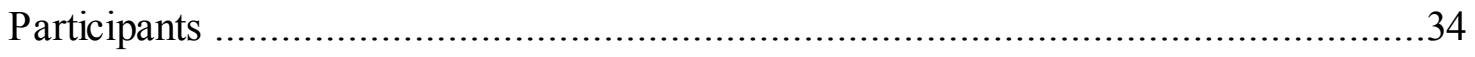

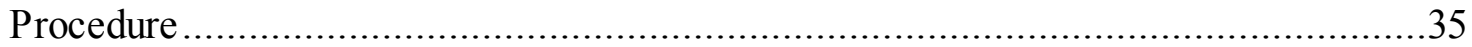

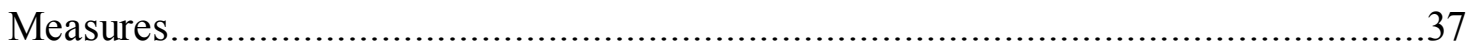



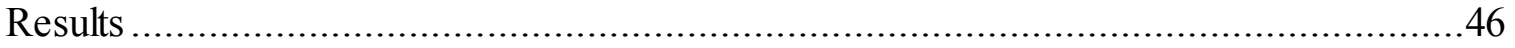

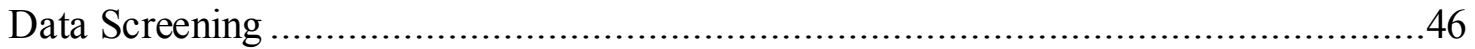

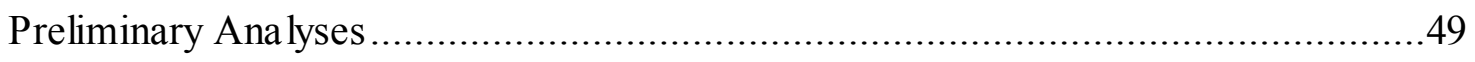

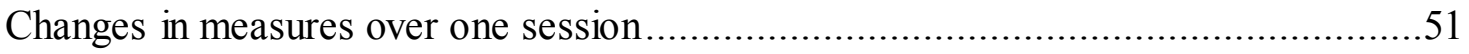

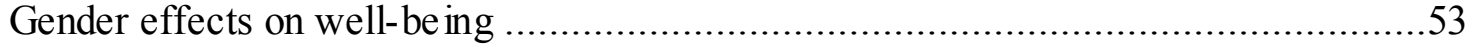

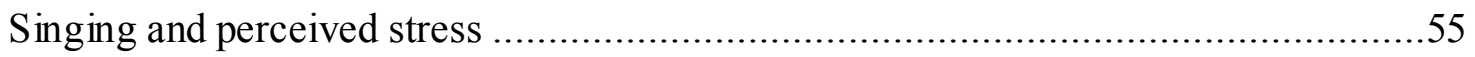

Exploration of singing, PA, and social bonding mediation ................................56

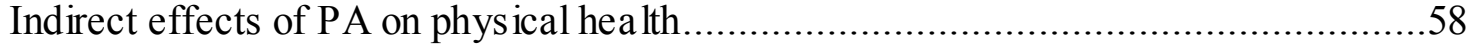




\section{WELL-BEING THROUGH SONG}

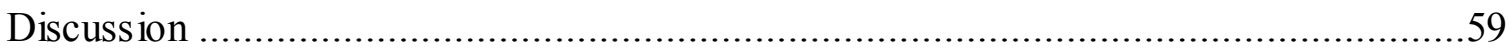

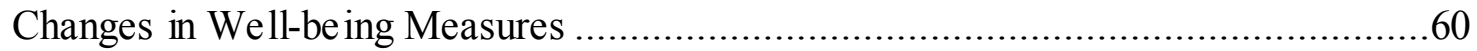

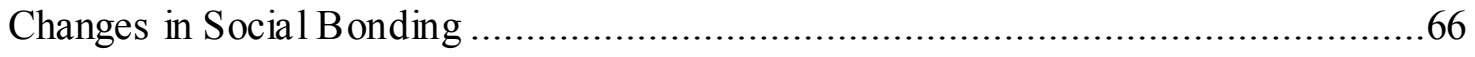

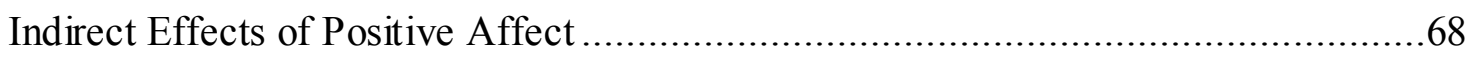

Gender Effects............................................................................... 71

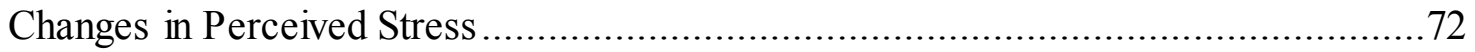

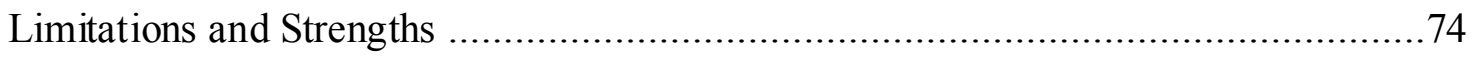

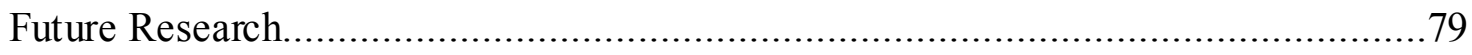

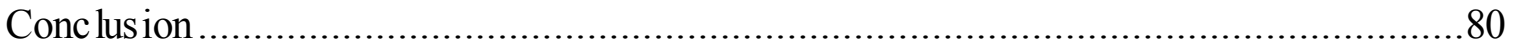

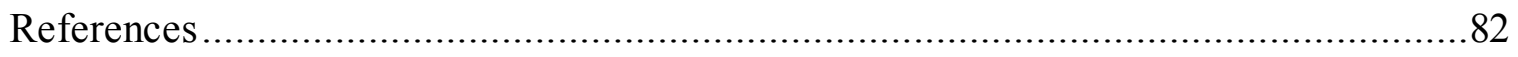

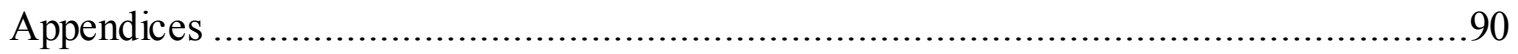

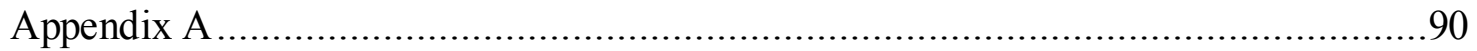

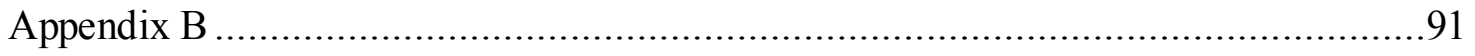

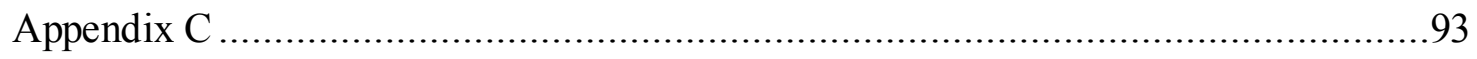

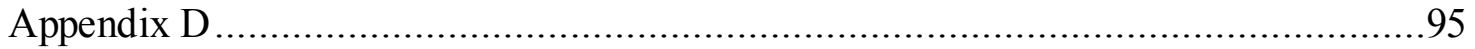

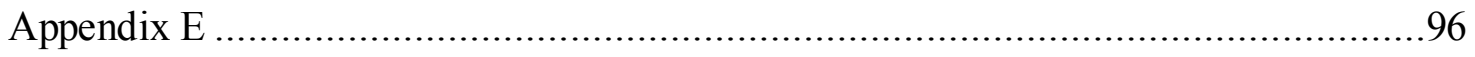

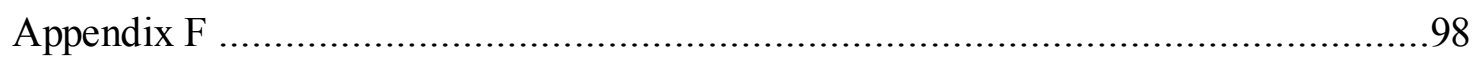

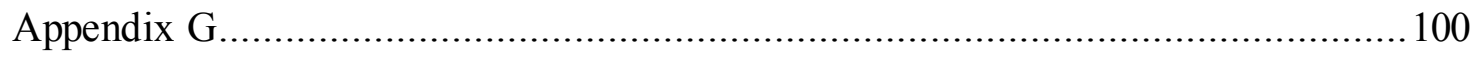

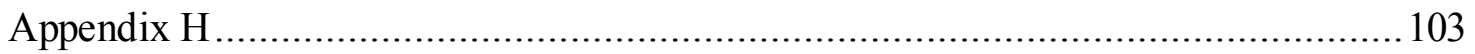

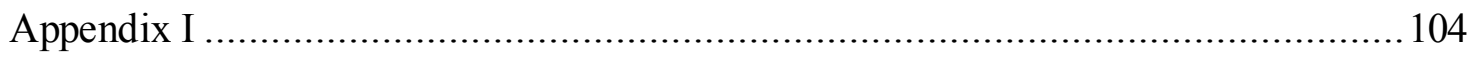

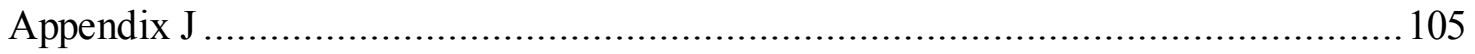

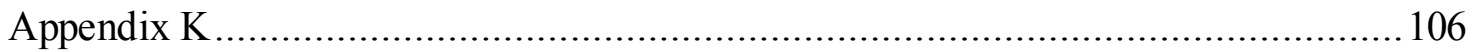

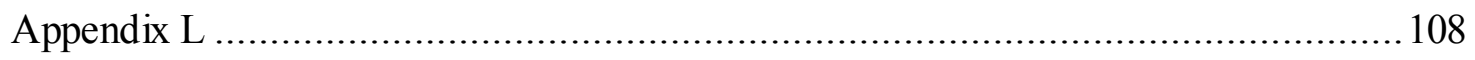


WELL-BEING THROUGH SONG

\section{List of Tables}

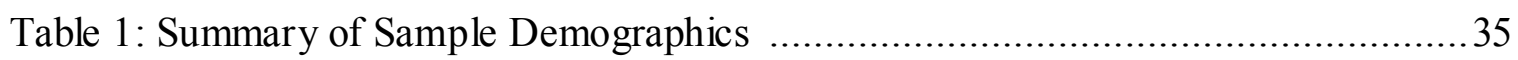

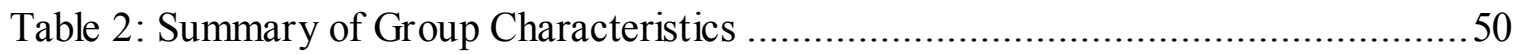

Table 3: Descriptive statistics for positive affect, social bonding, and vitality ................53 
WELL-BEING THROUGH SONG

\section{List of Appendices}

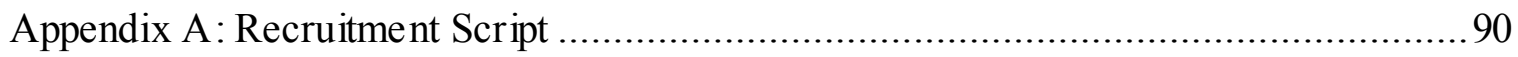

Appendix B: Informed Consent Form ....................................................... 91

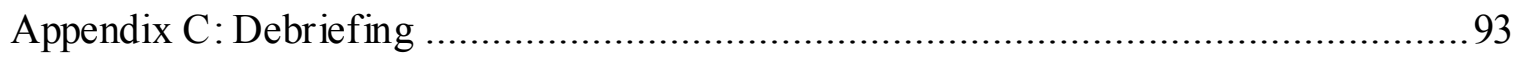

Appendix D: Satisfaction with Life Scale ................................................... 95

Appendix E: University of Queensland Quality of Life Instrument ...........................96

Appendix F: Demographic and Background Information ................................. 98

Appendix G: Le isure Activities Scale ........................................................... 100

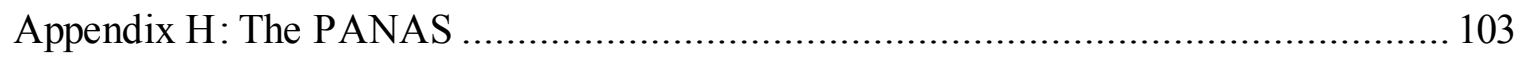

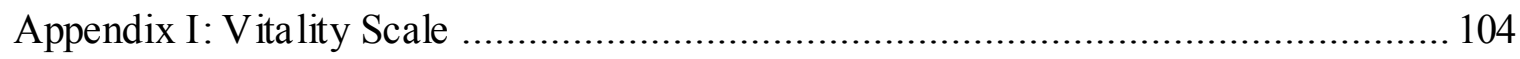

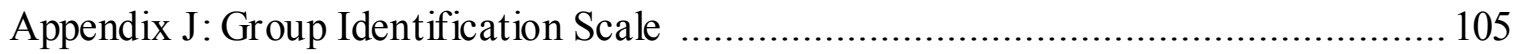

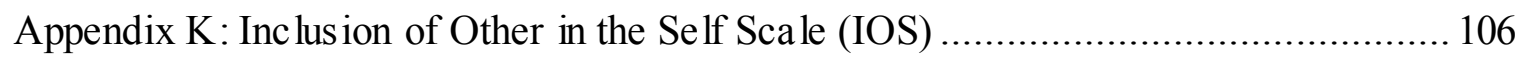

Appendix L: Pearson Correlations between dependent variables ............................ 108 


\section{WELL-BEING THROUGH SONG}

Well-being through Song: A Biopsychosocial Examination of Singing and Well-being in Community Dwelling Older Adults

By 2055 it is expected 25 percent of Canada's population will be over the age of 65 (Statistics Canada, 2015). Moreover, as of July 2015 the population proportion of older adults (over age 65) now outnumbers children (aged 0 -14) for the first time in Canadian history (Statistics Canada, 2015). The rise of this age group presents a unique challenge to Canada's health care system. Approximately 81 percent of community dwelling older adults live with some type of chronic condition (Gilmour \& Park, 2006); however, these conditions do not necessarily impact daily functioning (Chappell \& Hollander, 2013). In addition to potential physical declines, issues pertaining to the mental well-being of older adults are also crucial to address. One such issue is social isolation, which in addition to negative psychological (e.g., loneliness and depression) and social (e.g., lack of social support) consequences can increase the risk of negative health behaviours (e.g., smoking, drinking, poor eating habits, physical inactivity, and increased likelihood of falls; National Seniors Council, 2014). With this demographic shift in mind, it is now more important than ever to consider methods of health promotion to not only enhance the quality of life of our older population, but also potentially reduce demands on the health care system.

One possible cost-effective method for improving older adult health is increasing opportunities for social participation. Social participation has been suggested to have a wide range of positive health outcomes for older adults, including reduced risks of depression, disability, and mortality, as well as improved cognitive health, better health behaviors, and higher self-rated health (Gilmour, 2012). Moreover, a growing body of 


\section{WELL-BEING THROUGH SONG}

research suggests engaging in leisure activities is a potential pathway by which subjective well-being may be enhanced (Kuykendall, Tay, \& $\mathrm{Ng}$, 2015). These findings may be particularly relevant to older adults as the relation between leisure engagement and subjective well-being has been found to be even stronger in retired individuals (Kuykendall et al., 2015). Taken together, extant research provides promising evidence that leisure activities may benefit health in multiple domains, which in turn suggests leisure engagement may be a useful way to enhance older adults' health and well-being. Healthy aging is defined by Health Canada (2002) as " a lifelong process of optimizing opportunities for improving and preserving health and physical, social, and mental wellness, independence, quality of life and enhancing successful life course transitions" (as cited in Chappell \& Hollander, 2013, p. 25). With this definition in mind, efforts to improve health of older adults should be considered using a biopsychosocial framework (Engel, 1977) in order to account for both the individual and collective influence of physical, social, and psychological components of well-being.

Pressman and colleagues (2009) is one of the few studies to explore the health benefits of leisure activities from a psychological viewpoint using a biopsychosocial framework. Data from four separate studies were combined to form the large sample ( $n$ $=1399)$, which ranged in age from $19-89$ years and had a median age of 72 . Among these four studies, two of the studies recruited participants with conditions associated with increased age (i.e., menopause and osteoarthritis). Pressman et al. (2009) posit leisure activities might be beneficial in respect to coping with and buffering stress. While many previous studies have looked at just one activity and had a tendency to focus on physical activities, Pressman and colleagues wanted to focus on a broad spectrum of 


\section{WELL-BEING THROUGH SONG}

leisure activities, especially those that might offer an opportunity to recharge or a diversion from stress. The Pittsburgh Enjoyable Activities Test (PEAT) was designed specifically for the study and included ten different leisure activities: spending quiet time alone; spending time unwinding; visiting others; eating with others; doing fun things with others; club, fellowship, and religious group participation; vacationing; communing with nature; sports; and hobbies (Pressman et al., 2009). Potential benefits of leisure activities on various psychological attributes were assessed using measures of positive and negative affect, depressive symptoms, life satisfaction, and purpose. Measures of social network diversity and size, as well as social support were also included. Physical benefits were also assessed and included measures of health behaviours such as sleep quality and physical activity, as well as physiological measures such as body mass index (BMI), waist circumference (WC), blood pressure (systolic and diastolic), and salivary cortisol. Demographic characteristics such as being female and Caucasian, as well as having higher income and education were all related to more frequent engagement in leisure activities. Results suggested more frequent engagement in leisure activities was associated with numerous psychological benefits including greater positive affect, life satisfaction, and purpose, as well as lower negative affect and fewer depressive symptoms. Pressman and colleagues also found evidence suggesting greater leisure engagement may buffer the negative psychological impact of stressful life events. In other words, when faced with highly stressful life events those individuals high in leisure engagement demonstrated lower levels of negative affect and higher levels of positive affect than those low in leisure engagement. Social benefits such as greater social support and larger and more diverse social networks were also found to be associated 


\section{WELL-BEING THROUGH SONG}

with more frequent leisure engagement. Furthermore, frequent leisure engagement was associated with a wide range of physical benefits including lower blood pressure, cortisol, WC, and BMI, as well as more exercise and better sleep quality. Participants who reported more frequent leisure engagement also reported better self-perceived physical health. The buffering effect of increased leisure engagement was also explored with physiological measures of stress; however, no stress buffering effects were found with physiological outcome measures.

Pressman et al. (2009) provide a wealth of suggestive yet certainly not conclusive evidence for psychological, physical, and social benefits of engaging in a variety of leisure activities in a frequent manner. In particular, questions remain about the mechanisms behind these effects. Pressman et al. (2009) did explore one potential mechanism by examining the frequency of leisure activities (i.e., PEAT score) as a mediator between SES and physical health and found including PEAT scores reduced the associations between SES and health. However, it is unclear whether the health benefits are a result of a direct relationship with physical functioning or a more indirect effect such as social or emotional impacts of leisure engagement, or stress buffering (Pressman et al., 2009). In addition, despite the fact that a wide range of leisure activities was studied, the unique impact of different categories of activities was not explored. Moreover, it is difficult to know what specific types of activities participants were engaged in, as the PEAT categories were quite broad. By way of example, Pressman and colleagues did not specifically include an item pertaining to musical activities such as singing, but it is quite possible that some individuals may have been participating in musical activities such as choirs. Although group singing may have been considered by 


\section{WELL-BEING THROUGH SONG}

participants to fit under categories such as fun things with others, clubs, or hobbies, it was not clearly isolated or included among the leisure activities studied.

Singing for health and well-being is an area of research that is rapidly expanding. Past reviews have demonstrated singing may offer potential health benefits in biological, psychological, and social domains; however, methodological flaws such as lack of control and use of small exploratory samples have yielded insufficient evidence to draw evidence-based conclusions (Clift, Hancox, Staricoff, \& Whitmore, 2008; Clift, Nicol, Raisbeck, Whitmore, \& Morrison, 2010; Gick, 2011). The focus of the present study is on singing as a way to enhance the health and well-being of our older population. The review that follows will explore extant singing research from a biopsychosocial perspective concentrating on potential health and well-being benefits for older adults. While most of the studies conducted with older adults utilize group singing, the few solo studies that exist are reviewed where appropriate. Due to the limited number of studies conducted with this population, studies in which samples are not comprised exclusively of older adults will also be included in cases where the mean age was close to 60 or the age range extended well into advanced years. Studies of exclusively younger adults and studies of children and adolescents are excluded from this review.

Many studies examining health benefits of singing do so within a music therapy context, in which singing is treated as an intervention for various conditions. For example, past studies have explored singing as a pain intervention for individuals with chronic pain, as well as individuals with IBS (see Clift et al., 2010, and Gick, 2011 for reviews). Numerous studies have also explored singing as an intervention for individuals with breathing problems such as COPD, asthma, and sleep-disordered snoring (see Clift 


\section{WELL-BEING THROUGH SONG}

et al., 2010, Gick, 2011, and Gick \& Nicol, 2015, for reviews). Still other studies have examined singing as a more psychological form of intervention, such as an alternative to medication for reducing anxiety and depression following surgery or as a means of enhancing purpose and meaning in homeless individuals (see Clift et al., 2010 \& Gick, 2011 for reviews). Research on singing as a therapeutic intervention for Alzheimer's disease and other dementias is also rapidly expanding. A review of studies with this population suggests group singing may increase social behaviours, encourage participation, and reduce anxiety and agitation [(Clift et al., 2010); for further review of studies pertaining to dementia and singing see reviews by Clift et al. (2010) and Gick (2011)]. Although most older adults have some form of chronic condition (i.e., $81 \%$ of community dwelling older adults; Gilmour \& Park, 2006) this review will exclude studies exploring singing as treatment for specific health problems (e.g., COPD). The present study will instead review what might be considered "wellness studies" which focus on promoting physical, psychological, or social health in cognitively healthy older adults (Noice, Noice, \& Kramer, 2014). While the following review will focus primarily on community dwelling older adults, studies conducted in retirement homes are included where appropriate (i.e., samples are verified as cognitively and physically healthy). Although none of the studies presented report administering formal measures of cognition, several researchers indicated participants did not have a known diagnosis of dementia or other cognitive difficulties.

The review will follow a biopsychosocial framework and includes the potential of singing for maintaining and improving health in terms of physical, social, and psychological well-being. Studies exploring potential psychological benefits of singing 


\section{WELL-BEING THROUGH SONG}

in healthy older adults are examined first, followed by studies of physical benefits, and, finally, social benefits are reviewed. Recall the biopsychosocial model recognizes there are multiple domains that contribute to health, thus biological factors may interact with psychological and social factors and vice versa (Engel, 1977). In this respect, some studies reviewed explore benefits to multiple domains. Studies that include more than one domain of measure (i.e., not just psychological, physical or social) are introduced in full detail in the first domain they appear (e.g., psychological) and discussed only in terms of domain specific findings in later review sections.

\section{Older Adults and Singing}

\section{Psychological Benefits}

Among the most prevalent reported benefits of singing are those impacting psychological well-being. These benefits can be broken down into two categories of psychological well-being: hedonic well-being and eudaimonic well-being. Past reviews of singing and well-being in the general population suggest singing might induce hedonic benefits such as positive mood, increased life satisfaction, as well as eudaimonic benefits such as purpose, personal growth, and mastery (Gick, 2011). Studies exploring psychological benefits of singing for older adults will be reviewed below. The majority of studies with this sample examine hedonic well-being; however, studies of eudaimonic well-being are included where available.

In an early study, Wise, Hartmann, and Fisher (1992) explored potential benefits of choral singing in older adults. Members of a retirement community choir $(n=49$; mean age $=64.1$ years $)$ and randomly selected non-choral members of the same retirement community $(n=49$; mean age $=65$ years $)$ completed questionnaires about 


\section{WELL-BEING THROUGH SONG}

health status, participatory activities, and well-being. Additionally, choral members were asked in an open-ended question to explain why they sang. The groups did not differ significantly in health status, life satisfaction, or alienation. A simple love for singing and the enjoyment gained from associating with choral members were among the most popular reasons why individuals sang with the choir. The use of a quasi-control group of non-singers provides strength to this study.

In contrast to Wise and colleagues (1992), Johnson et al. (2013) also examined possible benefits in older adult community choirs, but did not implement a control group. Specifically, they assessed perceived benefits of group singing, as well as quality of life and depressive symptoms. Participants $(n=117$; mean age $=71.6$ years $)$ were recruited from eight different choirs in Jyväskylä, Finland. Those who reported greater perceived benefits of singing (i.e., emotional, relaxation, social support, health, and motivations) also reported greater overall quality of life, especially in the psychological and social relationship domains. Moreover, participants reported few depressive symptoms. The lack of control group in the study presents a limitation, as it is unclear whether the high quality of life and low number of depressive symptoms could be attributed to singing itself.

Similarly, Hillman (2002) did not use a traditional control group in her study of perceived benefits of participating in group singing. The sample was drawn from the community group Call That Singing? (CTS) and the 75 participants were over the Scottish age of statutory retirement (i.e., men over 65 and women over 60 years). Participants were asked to reflect upon their own perceived health and well-being, before and after joining CTS. Results indicated significant perceived improvements in 


\section{WELL-BEING THROUGH SONG}

emotional well-being, self-confidence, understanding of singing, and quality of life since joining CTS. The retrospective nature of the study presents a potential limitation of these findings (Gick, 2011). For example, as the range in duration of CTS membership was quite wide (i.e., 6 months -11 years), it is possible that participants may not have been able to accurately recall specific aspects of their health and well-being prior to membership. While comparisons were made where possible to data from a national sample (e.g., perceived general health of CTS group compared to perceived general health data from the Greater Glasgow Health Board) a more rigorously controlled study is still needed.

Unwin, Kenny and Davis (2002) improved upon methodological weaknesses noted in various other studies by using not only a control group, but also random assignment in their study of the potential impact of group singing on mood. The age range of the sample was quite large (18 - 73 years); however, the majority of the group was older and fell between the ages of 55 and 65. Participants were randomly assigned to either a singing group or a control group that listened to singing. Mood states were assessed via the Profile of Mood States Questionnaire (P.O.M.S.; McNair \& Droppleman, 1981) prior to singing or listening, immediately after the 30-minute session, and one week later. Although a trend of larger effects was found in the singing group, no significant differences in mood were found between the singing and listening groups. Both groups did, however, demonstrate significant positive changes in mood across time, specifically on the P.O.M.S. subscales of tension, anger, vigour, fatigue, and confusion. These positive changes in mood were more pronounced at the immediate post-test than at the one-week follow up. Unwin and colleagues (2002) recognize a need for further 


\section{WELL-BEING THROUGH SONG}

exploration of other dimensions such as physiological changes (e.g., breathing patterns) that might differentiate the benefits of singing from other activities such as listening. Nonetheless, their study demonstrates great strength due to its controlled nature and use of random assignment.

Houston, Mckee, Carroll, and Marsh (1998) also conducted a methodologically strong study of group singing in older adults through implementation of control groups and random assignment. Their study looked at the impact of humorous singing on anxiety and depression of older adults in long-term care residences. Sixty-one participants (mean age $=83.7$ years) considered to be cognitively and physically healthy were recruited from six long-term care residences. Participants were randomly assigned by residence to either a sing-along intervention group or a control group (i.e., usual activities). Since the effect of humor was being studied, the sing-a-long group consisted of one-hour weekly sessions in which the researchers sang and danced in a humorous way while encouraging participants to join in. Measures of anxiety, depression, and general health were collected via interviews at baseline and after five weeks of intervention (or control). Findings suggested significant reductions in anxiety and depression of participants in the sing-a-long group. The use of random-assignment of residences and a control group are definite strengths of this study. However, due to the combined use of humor and singing in the intervention, it is unclear whether these positive effects can be attributed to singing or are merely a result of the humorous activity (Gick, 2011).

Creech et al. (2013) also found positive psychological effects of musical involvement, but could not attribute these effects to any particular musical activity such 


\section{WELL-BEING THROUGH SONG}

as singing. Creech and colleagues explored the potential impact of active engagement in musical activities (including singing) on the subjective well-being and quality of life of older adults. The music group consisted of 393 participants from various community music programs including: steel pans, guitars, ukulele, recorder, keyboards, samba, songwriting, and singing. The music group was compared to a control group of 102 participants from other activities such as: language classes, art/craft classes, yoga, social support groups, a book club, and a social club. The overall age range of the sample was quite wide (43 - 93 years), with a modal age of 65 years. Subjective well-being was conceptualized as "the extent to which basic and universal human psychological needs are met" (Creech et al., 2013, p. 37). Participants completed questionnaires that included measures of quality of life and basic psychological needs at the beginning of the study and nine months later. Findings demonstrated that the music group was significantly higher than the controls on measures of control and pleasure. No significant changes were found in subjective well-being over the nine-month period. The use of a control group is a strength of this study, especially because it included a wide range of nonmusical activities for comparison. Another definite strength of this study was the theoretical content. Creech et al. (2013) reviewed several models of human psychological needs, many of which were aging centered and include aspects such as control and autonomy. Ultimately, they decided to approach the study from a needs satisfaction perspective, which included many elements drawn from Deci and Ryan's (2000) self-determination theory. The use of a theoretical framework to guide their study provides a major strength seldom seen in other studies in this area of research. That said, there were also several weaknesses as a result of the study design. While the music 


\section{WELL-BEING THROUGH SONG}

group was asked about musical background, the control group was only asked if music was important to them. First, it is unclear if there was any consideration of the music group's participation in other non-music activities. Second, and perhaps more important, it was not clear whether there was consideration of any musical activities that the control group may have been concurrently involved in. As previously noted, this design greatly limits the ability to attribute results to musical involvement. Moreover, since the wide range of musical activities was not assessed separately at any given point, it is difficult to confidently state whether one musical activity (e.g., singing) might have greater benefit than another (e.g., guitar).

Kreutz, Bongard, Rohrmann, Hodapp, and Grebe (2004) also made use of a control group in their study, which examined effects of group singing compared to listening on emotional affect and immune competence. Members of an amateur choir ranging in age from $29-74$ years $(n=31$; mean age $=56.9$ years $)$ served as their own controls. While the sample was not made up of exclusively older adults, it did include a large number of participants within the older demographic and is being reviewed as a result. The study consisted of two one-hour sessions one week apart. During the first session participants sang pieces from Mozart's Requiem and during the second session they listened to pieces from Mozart's Requiem. Before and after each session participants completed measures of affect (i.e., Positive and Negative Affect Schedule, PANAS; Watson et al., 1988) and provided saliva samples. Negative affect was found to decrease significantly in both the singing and listening conditions; however, positive affect only increased significantly following singing and not after listening. Results of physiological measures are discussed below in the review of physical benefits. While the use of 


\section{WELL-BEING THROUGH SONG}

participants as their own control is a strength of this study, limitations exist in the specific type of music used (i.e., classical) because it is impossible to know if these results are applicable to singing in general or merely classical singing (Kreutz et al., 2004).

Furthermore, the order of conditions creates a limitation of the study as singing always preceded listening; it is unclear if the results would be the same if Kreutz and colleagues varied the presentation of conditions among participants (Gick, 2011).

Despite limitations such as lacking control groups (Hillman, 2002; Johnson et al, 2013) and limited use of random assignment (Houston et al., 1998; Unwin et al., 2002) the aforementioned studies provide suggestive, but not conclusive evidence that group singing could provide many psychological benefits to older adults. These benefits may include reduction of depressive symptoms (Houston et al., 1998; Johnson et al., 2013), increased quality of life (Hillman, 2002; Johnson et al., 2013), positive changes in mood (Kreutz et al., 2004; Unwin et al., 2002), increased emotional well-being and self confidence (Hillman, 2002), reduction of anxiety (Houston et al., 1998), and increased control and pleasure (Creech et al., 2013).

\section{Physical Benefits}

In addition to numerous psychological benefits, singing may also afford physical benefits to those who partake in it. Reviews focusing on singing in the general population indicate singing may provide physical benefits such as better posture, improved breathing, reductions in stress, and increased immune response (Clift et al., 2008; Gick, 2011). To date, physical benefits of group singing have only been explored to a limited extent in studies of community dwelling older adults; however, extant research does show promise. Studies looking at the physical benefits of group singing for 


\section{WELL-BEING THROUGH SONG}

community dwelling older adults will be reviewed below. As a result of the scarce nature of studies of physical benefits in this population, a study of solo singing will also be included.

Cohen and colleagues (2006) explored the impact of community arts programs on well-being of older adults. While mental and social well-being were also considered, physical health was a key focus of the study. Using a quasi-experimental design, a choral group was formed to serve as an intervention group $(n=90$; mean age $=79$ years $)$ and was compared to a control group performing usual activities $(n=76$; mean age $=79.6$ years). Self-reported changes in physical and mental health, as well as social activities were examined over a 12-month period. Significant improvements in overall self-rated physical health were found in the choral group. In contrast, the control group demonstrated a decline in self-rated physical health. Further, compared to the control group, the choral group reported fewer doctor visits, falls, and medication use. While the use of a control group was a strength of this study, limitations can still be found in the methodology such as a lack of random assignment. An additional methodological limitation exists in the time frame of data collection; as measures were only collected at the beginning and end of a 12-month period it is unclear when exactly the cited benefits of singing occurred (Davidson et al., 2014). Recruitment notices specified participating in a choral group, thus there is possibly some self-selection bias at play as participants likely had a desire to sing.

Sakano et al. (2014) overcame this particular type of self-selection bias by including both participants who liked and disliked singing in their study of the impact of singing on the psychological well-being and physical condition (i.e., immune 


\section{WELL-BEING THROUGH SONG}

competence) of older adults. All participants, regardless of preference for singing, were asked to sing three songs of their choice (average singing time $=3$ minutes 50 seconds). Only after the singing session were participants asked to indicate whether or not they liked singing and whether they thought they were good singers. Of 44 participants (mean age $=64.1), 12$ indicated they disliked singing. Prior to and after singing, participants completed questionnaires containing measures of mood states (e.g., P.O.M.S.; McNair \& Droppleman, 1981). In addition to the P.O.M.S. measure, participants used a visual analog scale to rate the degree to which they agreed with a series of single mood-related adjectives (i.e., refreshed, comfortable, pleasurable, light-hearted, relieved, and relaxed). Physiological measures such as pulse rate, blood pressure, swallowing function, oral condition, and blood and saliva samples were also collected pre and post singing. A significant decrease in cortisol levels and increase in saliva production was found regardless of whether the participant liked singing. Significant improvements were found when comparing pre and post singing in degrees in which the participants reported that they felt refreshed, comfortable, pleasurable, light-hearted, relieved, and relaxed. A significant main effect of preference was also found in which those who disliked singing were much lower on the refreshed, pleasurable, and relaxed measures. While this study only examined solo singing, it presents promising evidence of both physical and psychological benefits of singing - particularly in terms of relaxation and stress reduction - which may be transferrable to singing in a group setting. Usage of pre and post measures, as well as including both participants who like and dislike singing are strengths of this study; however, limitations exist in the lack of a control group. Moreover, selfselection of songs introduces a potential confound as it is unclear whether participants 


\section{WELL-BEING THROUGH SONG}

selected songs of the same genre. By way of example, opera songs may require different breathing patterns than pop songs, which in turn may offer more or less benefit than other genres.

Kreutz et al. (2004) also examined immune competence in their previously discussed study of choral singing. Immune competence was assessed via saliva samples by levels of secretory immunoglobulin A (S-IgA) which is "a protein considered as the body's first line of defense against bacterial and viral infections of the upper respiratory pathway" (Kreutz et al., 2004, p. 624). Cortisol levels were also measured before and after singing through saliva samples. Kreutz and colleagues found a highly significant increase in S-IgA following the singing condition, but did not find any significant change after listening. In contrast, cortisol levels were found to decrease significantly after the listening condition, but demonstrated no significant change in the singing condition. One weakness of the study is that physical activity was not controlled for; Kreutz and colleagues posit that the singing condition may have required participants to be more active than the listening condition, which in turn could have resulted in the different immune responses.

According to both the self-reported and biological measures of the studies reviewed, community dwelling older adults may derive many physical benefits from singing. Among said possible benefits is improved self-rated physical health (Cohen et al., 2006). Biological measures also suggest potential for increased immune competence as a result of greater levels of S-IgA (Kreutz et al., 2004). Results are mixed in terms of the effects of singing on stress hormones such as cortisol. While Kreutz and colleagues (2004) found no significant changes in cortisol levels following group singing, Sakano et 


\section{WELL-BEING THROUGH SONG}

al. (2014) reported a significant decrease in cortisol after a solo singing session. Nonetheless, research suggests potential for community dwelling older adults to physically benefit from singing, whether these benefits are self-perceived or biologically measureable.

\section{Social Bene fits}

While physical and psychological benefits found may be similar to those in solo singing, group singing may offer a unique benefit above solo singing in terms of the added social component of the group activity. Past reviews of group singing in the general population suggest many perceived social benefits such as a sense of collective bonding, development of new friendships, increased social interaction, and social support (Clift et al., 2008; Gick, 2011). The following section will focus on studies demonstrating social benefits of group singing for community dwelling older adults.

Skingley and Bungay (2010) conducted a qualitative study to explore potential benefits of a United Kingdom community singing program for older adults called Silver Song Clubs. Social interaction was amongst the most commonly cited benefit of participating in these groups. Seventeen participants (mean age $=77$ years) from across six different Silver Song Clubs were interviewed using a semi-structured format. Interviews yielded six major themes: enjoyment, well-being and mental health, social interaction, physical improvement, cognitive stimulation and learning, and memory and recall. Similar to Wise et al. (1992), Skingley and colleagues found participants simply enjoyed participating in the singing sessions. In addition, many participants noted a boost in positive affect. Various responses from the interviews suggest that group 


\section{WELL-BEING THROUGH SONG}

singing offered numerous social benefits. Moreover, one participant cited companionship as a main reason she attended the club and she posited that other members would concur.

Participants in Hillman's (2002) aforementioned study of the Scottish community group Call That Singing? (CTS) also perceived many social benefits of belonging to a singing group. In response to an open question about changes since joining CTS, 22 percent of participants mentioned improvements to social life. Having an opportunity to "meet and talk to so many people" (Hillman, 2002, p. 166) and not be alone were popular responses in terms of social benefits. These social benefits were particularly well endorsed by a number of widowed participants. Moreover, Hillman stated travelling to and from the singing group provided an additional social benefit to some members as many car-pooled or took the bus or train together. While these qualitative findings are useful in illustrating the nature of the social benefits, a limitation exists in that these exploratory qualitative data were purely self-report without analysis by grounded theory or other qualitative methods to provide more solid evidence of these potential social benefits (Gick, 2011).

Kreutz (2014) improves upon this lack of formal social measures by assessing social bonding in a choral group via oxytocin. The hormone oxytocin is thought to be a "biological correlate of social affiliation" (Kreutz, 2014, p. 52), thus it was used to assess the potential of singing in producing a socio-biological bonding response. The sample was not exclusively older adults, however the median age was over 50 years and more than half of the participants were in the $50-65$ age range. Participants engaged in both a chatting $(n=25)$ and singing $(n=24)$ condition as their own controls. The singing condition consisted of a full group choir rehearsal, while the chatting condition was done 


\section{WELL-BEING THROUGH SONG}

in pairs and involved discussion of positive life events. In order to approximate equivalency among conditions the choir director read a paragraph aloud prior to the chatting to simulate verbal instructions given during choir rehearsal. Participants were seated throughout both conditions. For each condition a psychological feelings questionnaire was completed and a saliva sample was collected prior to the activity and 30 minutes after. Results indicated significant increases in positive feelings after both the chatting and singing conditions; however, negative feelings were found to only decrease significantly after singing but not chatting. Moreover, oxytocin was found to only increase significantly following singing. While these findings support the notion that group singing may produce a social bonding response, they are not without limitation. Kreutz recognizes a great limitation in comparing pairs to a larger group. Despite attempts to create equivalent conditions (e.g., both sitting and instructed by choir director), the confounding nature of comparing group singing to chatting in pairs makes it difficult to draw conclusions about singing itself, as it is not the sole difference between the conditions. Furthermore, similar to Kreutz and colleagues' 2004 study, this 2014 study did not counterbalance the order of conditions across participants and may be subject to possible order effects as a result of the singing condition always preceding the chatting. A lack of behavioral measures to assess social bonding is also problematic in that oxytocin is the only indicator of this social response and it is possible that the increase in oxytocin in singing could be reflective of something other than social bonding (e.g., stress reduction; Kreutz, 2014). Inclusion of behavioral measures would have helped provide additional support for the presence of a social bonding effect. Kreutz acknowledges the lack of behavioural measures, but suggests the desire to continue 


\section{WELL-BEING THROUGH SONG}

participating in the choir (shown by most members) demonstrates commitment and attachment to the choral group, which in turn supports the notion that social bonding occurred.

Pearce, Launay and Dunbar (2015) improved upon this lack of behavioural measures in their study of singing and social bonding. Participants ranging in age from $18-83$ years (mean age $=60$ years) attended classes set up for the study and were either in a singing group ( $n=64$; four singing classes) or a non-singing group ( $n=46$; two craft classes and one creative writing class). Measures of closeness, positive and negative affect, and pain tolerance were collected before and after class at outset (i.e., following the second or third class), as well as at three and seven month time points. Results from the first time point indicate the singing group experienced a significantly greater increase in both closeness and positive affect over a single class compared to the non-singing group; however, there was no significant difference on these measures between the groups at three and seven months later. Pearce et al. (2015) posit these results suggest singing bonds groups more quickly than other activities. Despite putting forth that singing might facilitate social bonding through positive affect, Pearce and colleagues did not test the suggested mediation, which is a great limitation of the study.

Social functioning was also assessed in a study by Cohen and colleagues (2006) through a variety of self-report measures. Recall that the aforementioned study by Cohen et al. (2006) compared a usual activities control group to a choral group over a 12-month period. Assessments related to social aspects included self-report measures of loneliness and engagement in activities. Both the control group and choral group decreased in loneliness from baseline to follow-up; however, the choral group was found to decrease 


\section{WELL-BEING THROUGH SONG}

to a greater extent. Moreover, a trend was found in the choral group in increasing number of activities, while the control group showed a decrease in number of activities. Cohen and colleagues suggest a sense of mastery and meaningful social engagement may be the driving force behind the choral group increasing their engagement in other activities. This study has several strengths including both the use of a control group and a strong theoretical background. As previously discussed many studies on group singing and well-being lack substantial theoretical grounding. This study is theoretically based upon well-known gerontological research, which posits that social engagement (Bennett, 2002) may lead to positive health outcomes in older adults.

Positive health outcomes of group singing in older adults were also explored by Davidson et al. (2014). Participants consisted of two groups; the first was formed of older adults who were receiving some form of assistance at home from the organization Silver Chain $(n=17$; mean age $=79$ years $)$ and the second was made up of individuals who responded to an advertisement in a local newspaper $(n=19$; mean age $=76$ years $)$. Both groups were screened to ensure participants did not have any cognitive or physical problems and were not currently involved in any other group singing activities. The singing intervention consisted of weekly 90 -minute group singing sessions over an eightweek period, which also included refreshments post-singing. Standardized measures of loneliness, as well as physical and mental health were collected at the beginning and end of the eight-week intervention. Semi-structured interviews were also conducted to gain insight into perceived benefits. No significant changes were found on standardized measures of well-being. Davidson and colleagues suggest the eight-week intervention may have been too brief to produce measureable changes in health and well-being. 


\section{WELL-BEING THROUGH SONG}

However, interviews revealed many perceived positive outcomes, particularly in the social realm, such as increased social contacts. For many participants the friendship aspect motivated them to join the group; almost three-quarters of participants indicated, "wishing to meet new friends" (Davidson et al., 2014, p. 101) as a reason for participating. Similarly to participants in the study by Hillman (2002), participants in Davidson et al.'s study indicated that sharing transportation to and from the singing group added another beneficial social component. While the use of multiple standardized measures provides strength above the many exploratory and descriptive studies in this area of research, definite limitations are present in the small sample size (Davidson et al., 2014) and the lack of control group.

The studies reviewed suggest community dwelling older adults may gain numerous social benefits from participating in group singing. Among the most commonly cited social benefits were forming new friendships (Davidson et al., 2014; Skingley \& Bungay, 2010). Similarly, improvements to social life and increased opportunities for interaction were also popular themes that emerged from participant responses (Hillman, 2002; Skingley \& Bungay, 2010). Both Davidson et al. (2014) and Hillman (2002) found that sharing transportation to and from the singing group served as a unique form of social benefit to choral members. Further social benefits of group singing include decreased loneliness (Cohen et al., 2006). Social bonding was also found to be accelerated in singing groups compared to other group activities (Pearce et al., 2015). Group singing was even suggested to produce biological evidence of social bonding through increases in oxytocin (i.e., a biological correlate of social bonding; Kreutz, 2014). 


\section{WELL-BEING THROUGH SONG}

\section{Summary}

Research suggests that singing may be beneficial for the health and well-being of older adults in many ways. Potential psychological benefits range from simple increases in positive emotions/mood (Creech et al., 2013; Hillman, 2002; Kreutz et al., 2004;

Skingley \& Bungay, 2010; Unwin et al., 2002), to certain aspects of personal growth such as increased self-confidence and sense of control (Creech et al., 2013; Hillman, 2002). Moreover, the act of singing may reduce certain symptoms of psychological distress such as anxiety (Houston et al., 1998) and depression (Houston et al., 1998; Johnson et al., 2013). Researchalso suggests that singing might be advantageous for the physical wellbeing of older adults. In this respect, studies suggest singing may boost the immune system (Kreutz et al., 2004), as well as increase various domains of self-rated physical health (Cohen et al., 2006). To date, it remains unclear whether singing may also reduce physical stress, since a group of researchers found significant decreases in cortisol levels following singing (Sakano et al., 2014), while others noted no significant change (Kreutz et al., 2004). Evidence suggests older adults may also reap various social benefits from participating in group singing. A number of studies found the development of new social relationships to be not only a major benefit, but also a primary reason for older adults to join singing groups (Davidson et al., 2014; Hillman, 2002; Johnson et al., 2013; Skingley \& Bungay, 2010; Wise et al., 1992). Furthermore, singing might actually facilitate both behavioural (Pearce et al., 2015) and biological changes (i.e., increase levels of oxytocin; Kreutz, 2014), which reflect social bonding. Other findings suggest engagement in group singing might reduce loneliness and increase participation in other social activities (Cohen et al., 2006). Despite various methodological limitations raised in the studies 


\section{WELL-BEING THROUGH SONG}

reviewed, it is important to note that in some cases the best methodological option is a quasi-experimental design. Having a pool of participants to draw from and randomly assign is not always feasible and being assigned to sing may even be rather distressing to certain individuals because as Chong (2010) and Sakano et al. (2014) demonstrate, not everybody likes to sing.

\section{Rationale}

Although the studies reviewed provide some evidence to suggest singing may benefit older adult well-being in psychological, physical, and social domains, extant methodological limitations within the body of research make it difficult to confidently draw conclusions. As noted in Clift and colleagues 2008 review of singing and health, many of the existing studies are qualitative and predominantly exploratory in nature. This is particularly true when it comes to studies of older adults. While some studies have included a control group, the type of comparisons makes it difficult to draw evidence-based conclusions about the unique benefits of singing. Popular comparisons include: controls partaking in usual activities (Cohen et al., 2006; Houston et al., 1998; Wise et al., 1992), or listening to music as opposed to singing (Kreutz et al., 2004; Unwin et al., 2002). Despite some strength offered by these types of controls, the question whether singing is more beneficial than other leisure activities remains unanswered. Creech and colleagues (2013) improve upon this limitation in some ways by comparing musical activities (including singing) to a variety of non-musical activities such as arts and crafts, book club, and yoga. That said, the combination of singing and other musical activities (e.g., guitars and keyboards) again prevents evidence-based conclusions about 


\section{WELL-BEING THROUGH SONG}

unique benefits of singing from being drawn. The present study attempted to improve upon this limitation by isolating group singing and comparing it to other musical and non-musical leisure activities (i.e., seniors bands and bridge clubs, respectively).

The largely exploratory nature of many of these cited studies creates another shortcoming within this body of research, which is a lack of theoretical grounding. As suggested by Gick (2011), the absence of a common theoretical framework may be a result of the wide variety of methodologies used and populations studied. Moreover, a lack of consensus exists in the operationalization of the terms health and well-being (Gick, 2011), which further complicates the comparison of studies within this area of research and limits the conclusions which can be drawn. The present study adopted a biopsychosocial conceptual framework (Engel, 1977), in order to explore how singing might affect biological, psychological, and social factors of health and well-being, both individually and through interactions among the factors. This framework has been successfully employed by past studies in the field of health psychology including Pressman and colleagues' (2009) study on leisure activities. While Pressman et al. (2009) demonstrated the value of this model in exploring the health benefits of leisure activities, they examined leisure activities collectively and failed to account for the individual impact of activities. The present study attempted to improve upon the aforementioned limitation by isolating the unique impact of leisure activities such as singing within this framework.

Another limitation present within this body of research is a lack of "progressive development" (Clift et al., 2008, p. 2), as studies continue to be exploratory in design and often fail to build upon the extant research. In this respect, a number of studies aim to 


\section{WELL-BEING THROUGH SONG}

demonstrate the presence of benefits from singing, but do not attempt to explain why these benefits might occur. Research needs to explore potential mechanisms of the relationship between singing and well-being. While some researchers have suggested potential mechanisms, these are seldom tested (Gick, 2011). The present study explored potential mechanisms such as positive affect and social bonding, as well as potential moderators such as gender.

Positive affect may be a particularly important variable to explore as literature reveals consistent patterns associating positive affect and physical health (see Pressman \& Cohen, 2005 for a review). Across the studies reviewed singing was often associated with increases in positive emotional states (e.g., Creech et al., 2013; Kreutz, 2014; Kreutz et al., 2004; Unwin et al., 2002). Positive affect may be especially important to older adults because strong support has been found across the literature for an association between positive affect and lower mortality rates (Pressman \& Cohen, 2005). Pressman and Cohen (2005) suggest stronger social networks, more positive and fewer negative interactions, and frequency of stressful events as potential important mediators to explore in future studies of the relationship between positive affect and health. The studies previously reviewed suggest group singing may have an impact on many of these potential mediators (e.g., strengthening social networks and increasing positive interactions). Pressman and colleagues (2009) study provided clear evidence that positive measures are associated with leisure activities, but as previously discussed did not examine the association with specific leisure activities such as singing. Moreover, Pressman et al. (2009) suggest leisure activities may be a unique pathway by which PA influences well-being, but state directionality of the relationship is unclear and the 


\section{WELL-BEING THROUGH SONG}

possibility of a feedback loop between PA and leisure activities cannot be ruled out. Furthermore, while both Kreutz (2014) and Pearce et al. (2015) studied singing and found increases in positive affect and social bonding, neither study tested a possible mediation. Thus, the present study explored the possibility of positive affect mediating the relationship between singing and social bonding. As suggested by Pearce and colleagues (2009), it is unclear whether PA might be acting as a mediator between leisure activities such as singing and other well-being variables, or whether the direction of the relationship goes another way. With this in mind, the present study explored PA as both a mediator and an outcome in the relationship between singing and social bonding (i.e., PA was the mediator and social bonding was the outcome variable in one model, and social bonding was the mediator and PA was the outcome variable in the other model). Gender is also a particularly interesting variable to examine in that females often outnumber males (approximately 3:1) in studies of singing and health, yet effects of gender are rarely considered (Clift et al., 2008). Clift and Hancox (2001) is one of the few studies of singing to consider the impact of gender and findings suggest women experience greater well-being benefits than men. In respect to gender, Pressman et al. (2009) also found significant gender differences in that women had higher PEAT scores (i.e., women engaged in more leisure activities than men). Higher PEAT scores were suggested to be associated with more positive psychosocial characteristics, better physiological function, and better health behaviours (e.g., better sleep and more exercise). Due to demographic patterns of the age group being studied as well as patterns consistent with singing groups, it is not surprising that women largely outnumber men in singing samples. The present study nonetheless explored gender as a moderator. 


\section{WELL-BEING THROUGH SONG}

Vitality is another variable that merits exploration in older adults. Busch and Gick (2012) studied the benefits of choral singing on psychological well-being and found, among other psychological variables (i.e., positive affect and personal growth), vitality showed significant increase after a single two-hour rehearsal. The study drew a sample from two existing choirs $(N=59)$ and asked participants to complete measures of hedonic and eudaimonic well-being before and after a choir rehearsal. While Busch and Gick's (2012) sample was not primarily older adults, it did contain adults in the older range $($ mean age $=55.92$ years; range $=28-80$ years $)$. Similar significant increases in vitality were also found to occur over 4 weeks in Gick and Daugherty's (2015) study of weekly singing as an intervention for asthma in a younger adult sample. Although vitality has been examined in adults, it has seldom been studied in solely older adult samples. Davidson et al.'s (2014) study is one of the few studies to explore vitality in a sample of community dwelling older adults and they found a significant decrease in vitality over eight weeks. Taking the aforementioned positive findings into consideration, the present study explored whether vitality might increase for community dwelling older adults in the context of a single singing session.

More generally, the present research continued to explore whether benefits of singing could occur within a single session. While many studies have used pre and post designs, much of these involve multiple singing sessions spanning over a series of several weeks (Davidson et al., 2014; Houston et al., 1998), months (Creech et al., 2013), or even years (Cohen et al., 2006; Cohen et al., 2007; Hillman, 2002). Still other studies have looked at the benefits of singing in an exploratory way and collected descriptive findings at only a single point in time (Johnson et al., 2013; Skingley \& Bungay, 2010; Wise et al., 


\section{WELL-BEING THROUGH SONG}

1992). Hillman (2002) also collected data at a single point in time by using retrospective self-reports to obtain information about perceived benefits before and after joining a singing group. Although findings from previous research suggest a single singing session can be beneficial physically (Kreutz et al., 2004; Sakano et al., 2014), psychologically (Busch \& Gick, 2012; Kreutz, 2014; Kreutz et al., 2004; Pearce et al., 2015; Unwin et al., 2002), and socially (Kreutz, 2014; Pearce et al., 2015) questions remained in terms of what specific benefits may be obtained. Psychological, social, and physical benefits of a single session were further examined to build upon the knowledge of existing benefits and potentially replicate past findings (e.g., increases in positive affect, vitality, and social bonding over a single session).

Other important considerations included the use of reliable and valid quantitative measures as a means of building upon the existing qualitative findings. By way of example, a number of positive social benefits have been reported via open response questions and semi-structured interviews (Hillman, 2002; Skingley \& Bungay, 2010), however, there is a lack of findings from quantitative social measures or more advanced qualitative methods (e.g., thematic analyses) to provide additional support for these claims. This study integrated a variety of reliable and valid quantitative measures in order to expand upon past descriptive studies.

\section{Objectives}

As illustrated by the above review, singing is an activity that has many potential benefits for older adults; however, it is unclear whether singing affords any additional benefits above those associated with general leisure engagement. As such, the first goal of this study was to compare group singing to other leisure activities in order to explore 


\section{WELL-BEING THROUGH SONG}

whether singing offered any unique benefits above and beyond those associated with leisure engagement alone. This was important to investigate because previous studies have not offered strong comparisons (if any) of singing and other activities. Moreover, both musical (i.e., seniors band) and non-musical (i.e., bridge club) control activities were selected in order to further assess whether merely active music engagement was beneficial or whether singing possessed unique benefits. In addition to a lack of research exploring the unique benefits of singing, few researchers have attempted to address why these benefits might occur. The second goal of this study was to address that problem by examining potential mechanisms by which these benefits might occur, as well as the influence of potential moderators on whether or not these benefits occur. The third goal of this study was to explore whether benefits could occur over a single session.

\section{Hypotheses}

\section{H1: Increase in positive affect will be higher afte $r$ one session of singing than one} session of each of the non-singing group activities (i.e., band and cards separately). Previous findings indicate a single session of singing may increase positive affect (Busch \& Gick, 2012; Kreutz et al., 2004; Pearce et al., 2015). Other studies provide similar findings following singing, including positive mood changes (Unwin et al., 2002), increased positive feelings (Kreutz, 2014), and increased pleasure (Creech et al., 2013). In cases where singing was compared to other activities, these positive changes were found to typically be larger in the group that included singing (Creech et al., 2013; Kreutz et al., 2004; Pearce et al., 2015; Unwin et al., 2002).

\section{H2: Incre as e in social bonding will be gre ater afte $r$ one session of singing than} one session of each of the non-singing group activities (i.e., band and cards 


\section{WELL-BEING THROUGH SONG}

separately). Pearce et al. (2015) acknowledge that their study does not differentiate between the bonding effects that may occur as a result of a shared group goal (i.e., performing a song together) and those occurring due to singing itself, and suggest future research should explore this. The present study provided an avenue to test this, by comparing singing to activities with (i.e., instrumental band) and without (i.e., bridge club) shared group goals. Past studies suggest when compared to other (non-musical) activities, participants in singing groups have demonstrated greater increases in social bonding over a single session (Kreutz, 2014; Pearce et al., 2015). While Pearce and colleagues (2009) found these differences between singing and non-singing were only present early in the group's formation (i.e., when measured pre/post $2^{\text {nd }}$ or $3^{\text {rd }}$ rehearsal, but not pre/post rehearsals occurring three and seven months later), Kreutz (2014) found group differences nearly two months after group formation (i.e., at the $7^{\text {th }}$ or $8^{\text {th }}$ rehearsal). It was anticipated that similar effects would be found when comparing singing to a non-musical control group activity (i.e., playing cards). Though exploratory, it was also expected that the increase in social bonding would be greater after one session of singing compared to one session of band. It was posited that as opposed to using different instruments like the band, everyone in the singing group is using the same instrument (i.e., voice), which might make them feel more similar and thus more bonded with the other members of the group.

\section{H3: Positive affect is anticipated to mediate the effect of singing on social}

bonding. As suggested by Pearce et al. (2015) "singing may have evolved to quickly bond large human groups of relative strangers, potentially through encouraging willingness to coordinate by enhancing positive affect" (p. 1). While Pearce and 


\section{WELL-BEING THROUGH SONG}

colleagues (2015) found that singers experienced a significantly greater increase in both closeness and positive affect during a single session than non-singers, they did not test whether positive affect mediated the relationship between singing and closeness. Studies such as Pressman et al. (2009) also suggest a potential pathway exists between leisure activities and positive affect, but indicate the direction of the relationship is unclear and this as an area for future research to explore. Thus, this hypothesis addresses issues highlighted by previous research. Given the exploratory nature of this hypothesis, it was recommended that mediation analyses be performed with PA as the mediator and social bonding as the outcome, as well as with PA as the outcome and social bonding as the mediator in order to better establish the nature of this hypothesized relationship.

\section{H4: Women who are singers will experience greater subjective well-being} benefits than men who are singers. In the sole study to explore gender differences in singing and well-being, women were found to experience greater well-being benefits than men (Clift \& Hancox, 2001). Pressman et al. (2009) also found women engaged in more leisure activities than men and more frequent leisure engagement was in turn associated with greater benefits across physical, psychological, and social measures. Subjective well-being is one of the most popular indices used across well-being research (Ryan \& Deci, 2001). The three components that make up subjective well-being are life satisfaction, presence of positive mood, and absence of negative mood (Ryan \& Deci, 2001). The present study examined whether the gender difference in well-being found by Clift and Hancox (2001) might be replicated using measures of subjective well-being (i.e., SWLS and PANAS). This hypothesis was exploratory and dependent upon sample demographics. 


\section{WELL-BEING THROUGH SONG}

\section{H5: Incre as e in vitality will be higher after one session of singing than one}

session of each of the non-singing group activities (i.e., band and cards separately). Past research has demonstrated vitality can increase following a single session of singing (Busch \& Gick, 2012); however, as of yet it was unclear whether this would hold true in sample of exclusively older adults. While physically demanding synchronous activities such as singing are thought to release oxytocin and $\beta$-endorphin, which are biological correlates of social bonding (Pearce et al., 2015), this physical exertion might also enhance feelings of vitality. The additional physical demands of singing (e.g., breathing control) were predicted to provide a unique boost to vitality above other less physical non-singing group activities, such as playing cards. The potentially physical demands of participating in a band may also evoke feelings of vitality, thus analysis offered an opportunity to explore whether the two musical groups differed significantly on this variable.

H6: Decre ase in perceived stress will be gre ate $r$ after one session of singing than one session of each of the non-singing group activities (i.e., band and cards separately). This hypothesis was exploratory and aimed to determine whether a single session of singing might decrease perceived stress and in turn whether this decrease would be greater than in other non-singing activities. Past research has demonstrated that engaging in leisure activities might buffer the effects of stress. For instance, Pressman et al. (2009) found that engaging in more frequent leisure activities moderated the effects of stress on positive and negative affect. In other words, stressful events had lesser negative impact on mood when individuals were high in leisure engagement compared to those 


\section{WELL-BEING THROUGH SONG}

who were low in leisure engagement. The present study explored whether singing possessed a unique buffering effect on perceived stress.

\section{H7: Positive affect is anticipated to mediate an as sociation be tween singing and} self-re ported phys ical he alth. One pathway by which singing affects health might be through positive affect. Singing has been found to increase positive affect in several studies (Busch \& Gick, 2012; Kreutz et al., 2004; Pearce et al., 2015). Research has also suggested singing might be linked to better self-reported health (Cohen et al., 2006). If positive affect predicts better physical health as suggested by Pressman and Cohen (2005), it was anticipated that singing might predict better health through increasing positive affect.

\section{Method}

\section{Participants}

Community dwelling older adults (aged 55 and older) were recruited from seniors' recreation centres in the Ottawa area (i.e., Good Companions Centre, Kanata Seniors Centre, Churchill Seniors Centre, Nepean Seniors Centre, and Abbotsford Community Programs), as well as through similar programs discovered through word of mouth. Participants in the singing group were members of existing choral groups associated with the aforementioned recreation centres. The musical and non-musical control groups consisted of participants in seniors' bands and bridge clubs, respectively, conducted at the same recreation centres. A total of 111 participants completed the study (singing $n=48$, bridge $n=32$, band $n=31$ ). Participants ranged from $56-92$ years of age $(M=72.96, S D=8.29)$. More than half of the participants were married and the majority identified as being Caucasian and financially comfortable. The sample as a 


\section{WELL-BEING THROUGH SONG}

whole was well educated; $62.6 \%$ of participants reported having over 12 years of education. Further summary of sample demographics can be found in Table 1. Fortyfive males and 66 females participated overall; however, the gender distribution varied across the groups (see Preliminary Analyses for further group characteristics).

Table 1

Summary of Sample Demographics

\begin{tabular}{ll}
\hline Variable & $\%(n)$ \\
\hline Ethnicity & $91.9(102)$ \\
Caucasian & $1.8(2)$ \\
Black & $2.7(3)$ \\
Asian & $.9(1)$ \\
Other & \\
Marital Status & $6.3(7)$ \\
Single - never married & $55(61)$ \\
Married & $1.8(2)$ \\
Separated & $14.4(16)$ \\
Divorced & $22.5(25)$ \\
Widowed & \\
Financial Status & $74.8(83)$ \\
Comfortable, don't worry too much & \\
about money & $24.3(27)$ \\
Making ends meet, getting by & $.9(1)$ \\
Struggling a lot, have some & \\
immediate financial concerns &
\end{tabular}

Note. $N=111$

\section{Procedure}

Following ethical approval from the Carleton University Research Ethics Board B (CUREB-B) groups willing to be contacted were approached for recruitment. A recruitment script (see Appendix A) was read to each group to explain the general purpose and voluntary nature of the research project (i.e., data would be anonymous, no incentives would be provided, and participants could withdraw at any time). In order to reduce any potential response bias, all prospective participants were provided with minimal information regarding the purpose of the study (i.e., participants were told that 


\section{WELL-BEING THROUGH SONG}

the study was on the potential impact of leisure activities on well-being in older adults) and were not given any indication that singing was the focus. The use of a script read by the researcher standardized the recruitment process so that all groups received the same information. One of the centres requested to do the recruitment itself and was provided with a copy of the same recruitment script in order to maintain consistency. Copies of the recruitment script were also distributed to prospective participants with hearing impairment to ensure complete understanding of participation.

After this recruitment phase, dates were arranged with each group during which questionnaires would be administered to those wishing to participate. Due to the fact that this study was exploring changes over a single session, questionnaires needed to be completed on site, immediately prior to and following the activity session (i.e., within one hour before and one hour after, otherwise ineligible). The activity sessions ranged from $1.5-2.5$ hours long $(M=2.28, S D=.32)$. Prior to completion of questionnaires all participants were asked to provide informed consent (see Appendix B). The questionnaires took approximately $30-40$ minutes overall to complete (i.e., $15-20$ minutes prior to activity and $15-20$ minutes following activity). The researcher was present during the course of all activity sessions and was available to answer questions while participants were completing the questionnaires. Following the completion of both questionnaires, all participants were given a written debriefing (see Appendix C), which provided further information about the goals and hypotheses of the study, and indicated how to deal with any questions or concerns. 


\section{WELL-BEING THROUGH SONG}

\section{Meas ures}

One-time measures. The following measures were completed only once, before or after their group session. Measures of life satisfaction and quality of life (which included self-reported physical health) were completed before the group activity, in case their completion was influenced by the activity. Demographics and the leisure activities measure were completed after the group activity.

Satisfaction with Life Scale (SWLS; Diener, Emmons, Larsen, \& Griffin, 1985). The Satisfaction with Life Scale (SWLS) is a measure used to assess global life satisfaction (see Appendix D). The brief five-item measure asks participants to rate their agreement with statements about their life (e.g., "If I could live my life over, I would change almost nothing" $)$ on a seven-point Likert scale $(1=$ strongly disagree to $7=$ strongly agree). A coefficient alpha of .87 indicates the SWLS has good internal consistency (Diener et al., 1985). The psychometric properties of the scale have also been assessed using older adult samples and the internal consistency remains good (Diener et al., 1985). The SWLS continued to demonstrate good internal consistency in this study $(\alpha=.86)$. In typical use, total scores are computed from the five items and range from 5-35; where a score of 5-9 indicates extremely dissatisfied, a score of 20 indicates neutral, and a score of 31 - 35 indicates extremely satisfied. The present study used a mean score as opposed to total score, in order to preserve sample size and deal with missing data. Mean scores were computed when responses were present for at least 4 of the 5 SWLS items. There was a perfect correlation $(r=1)$ between the total score and mean score. 


\section{WELL-BEING THROUGH SONG}

\section{The University of Queensland Quality of Life Instrument (UQQoL; Henwood \&}

Bartlett, 2008). The University of Queensland Quality of Life Instrument (UQQoL) is a 16-item measure of health-related quality of life (see Appendix E). The scale consists of nine domains: general health, physical well-being, physical aging, fatigue/sleep, mental well-being, role physical, bodily pain, social interaction, and body image. Participants are presented with 16 statements (e.g., "My physical ability concerns me"; "In day-to-day life aches and pains always affect me") and asked to rate the degree to which that statement is true for them using a five-point scale $(1=$ true to $5=$ never true $)$. A total score is computed from the 16 items and can range from $16-80$; where a higher score indicates greater health-related quality of life. Similar to the abovementioned SWLS scoring, a mean score was also computed for the UQQoL when at least 13 items were present to help minimize missing data. A perfect correlation $(r=1)$ was found between the total score and mean score. The UQQoL has demonstrated acceptable internal consistency $(\alpha=.72$; Henwood $\&$ Bartlett, 2008). In the present study, the scale demonstrated good internal consistency $(\alpha=.80)$. The scale has also shown good convergent validity when compared with another well-validated measure of health related quality of life, the Medical Outcome Survey Short Form (MOS SF-36; Ware \& Sherbourne, 1992). Specifically, the UQQoL summary score was found to correlate strongly with domains of the MOS SF-36 reflecting physical and functional health (Henwood \& Bartlett, 2008). Moreover, while the MOS SF-36 can be problematic because of frequent ceiling effects, the UQQoL summary scale was found to be "well within an acceptable floor and ceiling range" (Henwood \& Bartlett, 2008, p. 246). While some other widely used measures of quality of life such as the World Health 


\section{WELL-BEING THROUGH SONG}

Organization Quality of Life instruments (WHOQOL: OLD, BREF \& 100) assess social, psychological, and environmental factors, there is often little attention to physical factors (Henwood \& Bartlett, 2008). The UQQoL was designed with a focus on physical wellbeing and was created specifically for use with community dwelling older adults, which makes it ideal for the present study. Psychological and social well-being are examined extensively with other measures, thus a measure that emphasized physical well-being was essential in adhering to the biopsychosocial framework of the study.

Demographic and background information. Participants were asked to report their age, gender, education level, financial status, marital status, and ethnic/cultural identification in order to describe the sample (see Appendix F). Questions pertaining to their length of participation in the activity (i.e., choir, band, or card group), reasons for joining and staying with the group, and the extent to which they felt the activity was group-oriented or individually-oriented were also posed.

Leisure activities. Participants were asked to indicate the types and frequency of leisure activities they regularly engage in (see Appendix G). This measure was adapted from Pressman and colleagues PEAT measure (2009). In agreement with Pressman et al. (2009) existing leisure measures tend to be either too general or excessively specific and thus burdensome to complete. The PEAT was designed with the aforementioned issues in mind and includes a wide range of activities such as active and inactive, as well as solo and group activities. The present study drew upon the original 10 items of the PEAT to create a similar scale containing 12 items. Modifications to the original PEAT items included combining and/or eliminating items deemed too similar to one another (e.g., spending quiet time alone and spending time unwinding; visiting with others, eating with 


\section{WELL-BEING THROUGH SONG}

others, and doing fun things with others). Additional modifications included breaking down single items (e.g., separating clubs from fellowship and religious group participation) and expanding items (e.g., physical activities was added to sports). New items were also created (e.g., singing, playing a musical instrument, and games) to fit the interests of the present study and an "other" item was added to capture any activities not listed. Participants were asked to specify additional activity details where necessary. Also drawn from the PEAT, participants were asked to indicate how often they were able to engage in the listed activities over the last month using a scale from 0 to $4(0=$ never or do not enjoy and $4=$ every day). Directions to specify the numbers of hours per week for activities done once a week or more were added in order to offer a continuous measure of singing (i.e., hours sung per week) for the purpose of mediational analyses. Upon reviewing data collected on this measure it was unclear whether participants were reporting the estimated hours per week or the estimated hours per unit selected (e.g., hours per day). The "few times per week" response option further complicated this matter. As a result the continuous measure was coded according to the scale (i.e., $0-4$ ) and the estimated hours responses were ignored. Gathering the continuous singing data from within the larger leisure activity measure eliminated bias that may have occurred as a result of participants knowing the focus of the present study was singing.

Before and after measures. The following measures were completed twice, once before and once immediately after each session of group activity.

\section{Positive and Negative Affect Schedule (PANAS; Watson, Clark, \& Tellegen,}

1988). The Positive and Negative Affect Schedule (PANAS) is a widely used 20-item self-report scale used to assess positive and negative affect (see Appendix H). It consists 


\section{WELL-BEING THROUGH SONG}

of two subscales: 10-items assess positive affect (PA) and 10-items assess negative affect (NA). Examples of PA items include "interested" and "excited", and examples of NA items include "guilty" and "scared". Participants rate the extent to which they feel each item on a five-point scale $(1=$ very slightly or not at all, and $5=$ extremely $)$. Total PA and NA scores are computed by summing the items of each subscale. As missing data was particularly prominent in the PANAS, mean scores for PA and NA were used instead of total scores. The means were computed when responses were available for at least 8 of the 10 items. The mean scores correlated perfectly $(r=1)$ with the total scores. Various time instructions exist for this scale allowing researchers to select desired items such as: how the participant feels at the present moment, today, during the past few days, week, past few weeks, year, and in general. This study used the present moment instructions, which asks participants to rate what extent they currently feel a particular way. These instructions were used because the scale was administered before and after a single activity session in order to assess changes in PA or NA. Internal consistency for the general version of both the PA scale and the NA scale is good, with alpha reliabilities of .88 and .87 respectively (Watson et al., 1988). The scale reliability remains high when tested with older adult samples (Buz, Pérez-Arechaederra, Fernández-Pulido, \& Urchaga, 2015; Kercher, 1992). The PA scale with present moment instructions also demonstrated good internal consistency in the present study (before $\alpha=.89$; after $\alpha=.93$ ). The internal consistency of the NA scale was good as well (before $\alpha=.86$; after $\alpha=.84$ ).

Perceived stress. In the present study perceived stress was measured by proxy using selected items of NA: jittery, distressed, upset, nervous, and irritable. Mean scores 


\section{WELL-BEING THROUGH SONG}

were computed when 4 out of 5 items were present. The internal consistency of this proxy scale was found to be acceptable (before $\alpha=.81$; after $\alpha=.77$ ).

Vitality Scale (VS; Ryan \& Frederick, 1997). The Vitality Scale (VS) is a 6item measure used to assess subjective vitality (see Appendix I). Participants are presented with six statements (e.g., "at this moment, I feel alert and awake") and asked to rate the degree to which that statement is true for them using a seven-point scale $(1=$ not at all true to $7=$ very true). Typically, all six items are summed together then divided by six to compute an average score. Following similar computations done with other scales, mean scores were computed when 5 out of the 6 items were present. Higher scores indicate greater subjective vitality. While the original instructions ask participants to indicate the degree to which the statement is true "in general", the present study adopted the instructions used by Busch and Gick (2012), and Ryan and Frederick (1997) as a state vitality measure and asked participants to indicate the degree to which the statement is true "right now" because changes were examined before and after a single activity session. The VS has been found to demonstrate good internal consistency with both the original instructions $(\alpha=.84$; Ryan $\&$ Frederick, 1997) and the aforementioned modified instructions ( $\alpha=.92$; Busch $\&$ Gick, 2012). In the present study, the VS again demonstrated excellent internal consistency (before $\alpha=.94$; after $\alpha=.92$ ).

Group Identification Scale (GIS; Sani et al., 2015). The Group Identification Scale (GIS) is a 4-item measure of group identification (see Appendix J). The scale assesses group identification along two dimensions: sense of belonging to the group and sense of commonality. Participants are presented with four statements (e.g., "I have a sense of belonging to my [singing group/card group/musical band]") and asked to rate the 


\section{WELL-BEING THROUGH SONG}

degree to which they agree with each statement using a seven-point scale $(1=$ strongly disagree and $7=$ strongly agree). An average identification score is computed by summing the four items and dividing by four. Missing data was again minimized by computing a mean score when at least 3 of the 4 items were present. The scale has been validated in four studies (Sani et al., 2015). The first (mean age $=29.21$ years) and second (mean age $=29.65$ years) studies referenced family and found the scale had excellent internal consistency ( $\alpha=.92$ and $\alpha=.91$, respectively). The second study also referenced a group of friends and again demonstrated excellent internal consistency $(\alpha=$ .90 ). The third study (mean age $=21.11$ years) again referenced the family group and demonstrated excellent test re-test reliability $(r=.91)$ over a period of 18 days. The fourth study explored an older sample (mean age $=57.55$; range $=18-97$ years) and also showed excellent internal consistency with reference to family $(\alpha=.92)$, local community $(\alpha=.94)$, and a group of the participants' choice $(\alpha=.93)$. In the present study, the group activity was used as the reference group (i.e., band, choir, or card group) and the scale continued to demonstrate acceptable internal consistency (before $\alpha=.76$; after $\alpha=.82$ ). The GIS was selected not only because it is brief and has been found to have excellent psychometric properties, but also because it assesses sense of belonging/connectedness which may be indicative of social bonding. As Kreutz (2014) suggests, demonstrating commitment and attachment to the choral group might support the notion that social bonding occurred; likewise a sense of belonging and connectedness might also indicate this. Instructions were modified for each group (i.e., singing, band, and cards) so that the reference group reflected the activity being studied. Participants 


\section{WELL-BEING THROUGH SONG}

were asked to rate their agreement with each statement with the specified reference group in mind.

Inclusion of Other in the Self Scale (IOS; Aron, Aron, \& Smollan, 1992). The Inclusion of Other in the Self (IOS) is a single item pictorial rating scale of interpersonal closeness (see Appendix K). Participants are presented with a set of seven images, each of which demonstrates a different degree of overlap between two circles (i.e., similar to a Venn diagram) and are asked to circle the image that best describes their relationship with the specified "other".

Although many variations of this measure exist, the original measure contains one circle that represents "self" and one circle that represents "other"; starting out as two separate circles the two circles increasingly overlap over a series of seven steps. The present studied modified this measure so that one circle represented "me" and the other represented "my group", the instructions were also modified to match the group completing the questionnaire (i.e., they were asked to select the picture which best described their relationship with their choir or band or card group). Given that the IOS is a single-item scale, it is not possible to conduct many tests of reliability such as item analyses or inter-item consistency measures. With this in mind, Aron and colleagues (1992) created an alternate form using diamonds in the place of circles as a way to test reliability and found the scale to demonstrate excellent reliability $(\alpha=.93)$. Test-retest reliability of the IOS over a 2 -week period was also found to be good $(r=.83$, between first testing occasion and 2 weeks later). 


\section{WELL-BEING THROUGH SONG}

\section{Analysis Plan}

A repeated measures MANOVA was used with Pillai's Trace due to unequal $n$ (Tabachnick \& Fidell, 2007) to assess whether there were significant differences in changes in well-being and social bonding measures over a single session between singing and control groups (i.e., band and cards). Prior to analysis the data were evaluated to verify that the assumptions of repeated measures MANOVA were met (i.e., normality of sampling distributions, homogeneity of covariance, absence of outliers). Following the omnibus test of a predicted interaction between condition and time, univariate results were examined to better understand the change in the individual measures. Contrasts in the form of pairwise comparisons were used even if univariate results were not significant, as long as warranted by a priori hypotheses. Where assumptions of normality were not met (e.g., perceived stress data), nonparametric tests were used. Independent ttests were used to test gender effects in well-being.

For mediation analyses, OLS regressions were conducted using PROCESS macro for SPSS (Hayes, 2016). Indirect effects were also tested using bootstrapping via PROCESS. Although some researchers use the Sobel test, this method is problematic because it requires the indirect effect to meet the assumption of a normal sampling distribution (Hayes, 2009). Bootstrapping analysis was performed instead as it has been demonstrated to be a more a valid and powerful method, with a lower risk of Type I error (Hayes, 2009). A bootstrap sample is created by randomly sampling cases with replacement from the original sample in order to create an empirical representation of the sampling distribution (Hayes, 2013). A bootstrap sample of 5000 was used for each of the mediation models as recommended in the literature (Hayes, 2013). Weinstein, 


\section{WELL-BEING THROUGH SONG}

Launay, Pearce, Dunbar, and Stewart (2016) found group size might relate to social bonding, as social bonding effects (measured by the IOS) were significantly greater in larger less familiar singing groups compared to smaller more familiar singing groups. With these findings in mind, group size was entered into the models exploring social bonding as a covariate, in order to control for potential effects of variation in group size among the singing groups.

\section{Res ults}

\section{Data Screening}

All data were manually entered from the hard copy questionnaires. Random checks were performed using several questionnaires to ensure the values entered matched those of the questionnaire. Frequency tables were also used to check for out of range values indicative of data entry error.

Missing value analysis was conducted to assess whether there was a pattern

present in the missing data. Little's MCAR test was significant, $\chi^{2}(92)=160.71, p<.001$, indicating data was not missing completely at random (MCAR). Subsequently, separate variance t-tests were run in order to determine if data were missing at random (MAR) or missing not at random (NMAR). Significant separate variance t-tests suggest data were MAR. It is often suggested imputations be used rather than deletion to solve missing data problems when data are MAR; however, Allison (2014) posits listwise deletion provides an "honest" standard error compared to other forms of imputation and pairwise deletion which often provide incorrect estimates of both standard error and parameters. Taking this as well as the potential reduction in power (due to reduced $N$ ) into consideration, it was determined that listwise deletion would be the best option to deal with missing data. 


\section{WELL-BEING THROUGH SONG}

A total of 17 cases were deleted ( $\operatorname{singing} n=9$; cards $n=6$; band $n=2$ ). Following deletion there was a total of 39 participants in the singing group, 26 in the cards group, and 29 in the band group. Variables with more than $1 \%$ missing data included: IOS after, GIS after, PA after, and vitality before and after.

Boxplots were used to visually assess for univariate outliers and were followed up with z-scores to verify the potential outliers. One univariate outlier was detected on the before measure of the GIS using a cut-off value of $z=+/-3.29$. Analyses were conducted with and without the outlier present and it was not found to influence the significance of the results (i.e., findings that were previously significant remained significant at a similar value and vice versa). Thus, all cases were retained in order to preserve the already reduced sample size.

Histograms and P-P plots were used to visually assess normality and were followed up with calculation of standardized values for skewness and kurtosis in each variable. Standardized values were compared to a cut-off value of $z=+/-3.29$ (Kim, 2013). The before and after measures of NA were both found to be extremely positively skewed and kurtotic. On a $1-5$ scale, where 1 corresponds to very slightly or not at all and 5 to extremely, the mean for NA before activities was $1.3(S D=.43)$ and the mean for NA after was $1.1(S D=.26)$. Attempts were made to first inverse transform and then dichotomize the NA variable (i.e., $0=$ no negative affect, $1=$ some negative affect), however; the inverse transformed distribution remained significantly skewed and kurtotic. As result of this major departure from normality and the fact that NA would have only been used to test the gender and subjective well-being hypothesis, the NA variables were excluded from any further analyses. Although not as extreme as NA 


\section{WELL-BEING THROUGH SONG}

variables, the proxy measure of perceived stress computed from the NA items distressed, upset, irritable, nervous, and jittery also displayed significant departure from normality that was not improved by inverse transformation. Because testing of hypothesis 6 was dependent upon this variable, a non-parametric test (i.e., Mann-Whitney test) was used for any analyses of perceived stress. The before measure of GIS was found to be slightly negatively skewed. While a reflect and square root transformation was found to correct this, original data were maintained in order to avoid transformation of data at only one time point. The normality assumption was met in all other variables. Multivariate normality was also assumed on the basis of the univariate normality assumption being met (Field, 2005).

Data were assessed for multivariate outliers using Mahalanobis distance. Three scores were found to be multivariate outliers as they fell beyond the cut-off $\chi^{2}(12)=$ 32.91, $p=.001$. Similar to the analyses with univariate outliers, analyses were run with and without the multivariate outliers. The presence of these outliers was not found to significantly change the statistical findings; thus the cases were retained.

Multicollinearity was assessed via tolerance values. None of the dependent variables included in the MANOVA (i.e., PA, vitality, IOS, and GIS) were found to have a tolerance value below .20, thus it was concluded that none of the variables were conceptually redundant to one another (Huta, personal communication, January 2016).

Levene's test was used to assess homogeneity of variance among the dependent variables. Levene's test was not significant for $\mathrm{PA}, F(2,91)=.160, p=.852$; vitality, $F(2,91)=.879, p=.419 ; \mathrm{GIS}, F(2,91)=1.591, p=.209 ;$ or $\operatorname{IOS} F(2,91)=2.179, p=$

.119; thus the assumption of homogeneity of variance was met. Box M's test was also 


\section{WELL-BEING THROUGH SONG}

non-significant, $F(72,18942.2)=1.141, p=.194$, indicating the assumption of homogeneity of covariance matrices was met.

Pairwise correlations of all dependent variables at both time points (i.e., before and after) can be found in Appendix L. The dependent variables included in the MANOVA were found to be reasonably correlated (above .2, with the exception of vitality after and IOS before $r=.14$ ) therefore including them in the MANOVA as variables of a similar theme was justified (Huta, personal communication, January 2016). As expected, PA was significantly positively correlated with the other measures of wellbeing (i.e., vitality, SWLS, and UQQoL) and negatively correlated with measures of stress. PA was also significantly positively correlated with social bonding measures (i.e., GIS and IOS), which is also in accordance with existing literature (e.g., Pearce et al., 2015; Weinstein et al, 2016).

\section{Preliminary Analyses}

Exploratory analysis of various group characteristics was conducted prior to further analysis in order to better describe the sample. As noted in Table 2, the singing and bridge groups had more women and were more variable in size, while the bands had more men and were less variable in size. Across all groups, the nature of the activity (e.g., a love for singing) was the most common reason for both joining and continuing to participate in these activities; however, it was much more prevalent in the musical groups (see Table 2). Moreover, making new friends and doing the activity with existing friends were popular reasons among the card groups, but not so much among the musical groups. While the researcher considered the activities studied to be group-oriented activities, questions were included in the questionnaire to confirm this. Participants were given two 


\section{WELL-BEING THROUGH SONG}

scales (anchored by $1=$ not at all and $7=$ completely), one to rate the degree to which they felt their participation in the activity was group oriented and the other to rate the degree to which they felt it was individually-oriented (see Appendix F). Findings suggested the singing group felt the activity was not very individually-oriented $(M=$ $2.77, S D=2.05)$, but very much group-oriented $(M=6.26, S D=1.26)$. The band group found their activity to be slightly more individually-oriented than the singing group did $(M=3.20, S D=1.88)$, but still rated the activity high on group-orientation $(M=5.68, S D$ $=1.33$ ). Finally, the cards group rated their activity the highest of the three groups on individual orientation $(M=3.32, S D=1.85)$, but still found the activity more grouporiented $(M=5.38, S D=1.48)$.

Table 2

Summary of Group Characteristics

\begin{tabular}{|c|c|c|c|}
\hline Variable & Singing & Band & Cards \\
\hline \multicolumn{4}{|l|}{ Gender \% (n) } \\
\hline Male & $18.8(9)$ & $83.9(26)$ & $31.3(10)$ \\
\hline Female & $81.3(39)$ & $16.1(5)$ & $68.8(22)$ \\
\hline Age $(M, S D)$ & $71.55(8.88)$ & $72.16(7.73)$ & $75.90(7.34)$ \\
\hline Group size $(M, S D)$ & $29.56(12.89)$ & $12.35(4.88)$ & $22.31(14.06)$ \\
\hline Length of Participation ( $M$ years, $S D$ ) & $5.52(5.67)$ & $8.97(7.64)$ & $9.63(10.25)$ \\
\hline \multicolumn{4}{|l|}{ Reason for Joining $\%(n)$} \\
\hline Making new friends & $8.3(4)$ & 0 & $18.8(6)$ \\
\hline $\begin{array}{l}\text { Doing activity with existing } \\
\text { friend(s) }\end{array}$ & 0 & $6.5(2)$ & $9.4(3)$ \\
\hline The nature of the activity itself & $83.3(40)$ & $83.9(26)$ & $46.9(15)$ \\
\hline Other & $4.2(2)$ & $3.2(1)$ & $6.3(2)$ \\
\hline \multicolumn{4}{|l|}{ Reason for Continuing $\%(n)$} \\
\hline Making new friends & $8.3(4)$ & $3.2(1)$ & $12.5(4)$ \\
\hline $\begin{array}{l}\text { Doing activity with existing } \\
\text { friend(s) }\end{array}$ & $6.3(3)$ & $6.5(2)$ & $21.9(7)$ \\
\hline The nature of the activity itself & $64.6(31)$ & $74.2(23)$ & $46.9(15)$ \\
\hline Other & $10.4(5)$ & 0 & $3.1(1)$ \\
\hline
\end{tabular}

Note. $N=111$. 


\section{WELL-BEING THROUGH SONG}

\section{Changes in measures over one session}

H1, H2, and H5. In order to assess whether there were significant differences in changes in positive affect, social bonding, and vitality over a single session between singing and control groups (i.e., band or cards) a repeated measures MANOVA was used. Time (before and after) served as the within-subjects factor, condition (three levels: singing, cards, and band) was the between-subjects factor, and condition $\mathrm{x}$ time was the interaction. The dependent variables were positive affect, social bonding (i.e., IOS and GIS), and vitality. Means and standard deviations for the dependent variables are provided in Table 3. The repeated measures MANOVA revealed a significant multivariate main effect for condition, Pillai's Trace $=.168, F(8,178)=2.04, p=.044$, $\eta_{\mathrm{p}}^{2}=.08$. A significant multivariate main effect was also found for time, Pillai's Trace $=$ $.195, F(4,88)=5.32, p=.001, \eta_{p}^{2}=.20$. These main effects were qualified by a significant condition $\mathrm{x}$ time interaction, Pillai's Trace $=.226, F(8,178)=2.84, p=.005$, $\eta_{\mathrm{p}}^{2}=.11$. Univariate analyses were subsequently examined to better understand the nature of this interaction. The condition $\mathrm{x}$ time interaction was found to be significant for PA, $F(2,91)=9.13, p<.001, \eta_{p}^{2}=.17$, and vitality, $F(2.91)=6.01, p=.004, \eta_{\mathrm{p}}^{2}=.12$, but not for social bonding; GIS, $F(2,91)=.001, p=.999, \eta_{\mathrm{p}}^{2}<.001$, and IOS, $F(2,91)=$ $.93, p=.399, \eta_{\mathrm{p}}^{2}=.02$.

Exploration of the univariate results was followed up with tests of the a priori hypotheses using pairwise comparisons. A Bonferroni correction (requested and applied automatically through SPSS contrasts) was applied to adjust for multiple comparisons. Considering first PA and vitality, results indicated that the three groups did not differ significantly prior to engaging in the activity (all $p \mathrm{~s}>.5$ ). Post activity engagement, the 


\section{WELL-BEING THROUGH SONG}

singing group reported significantly higher PA than the cards group $(p=.003)$ and a strong, but non-significant trend of higher PA than the band group $(p=.069)$, while the band and cards group did not differ from each other $(p=.893)$. Further pairwise comparisons of the change in PA across activity session indicated that while the singing group reported increasing in PA, this change was merely a non-significant trend, $(p=$ $.125)$. On the other hand, both the cards $(p=.002)$ and band $(p=.001)$ groups demonstrated significant decreases in PA across the activity session. These findings partially support hypothesis 1 , albeit not in the predicted way. The singing group showed a trend to increase, as compared to the non-singing control groups that significantly decreased.

The pairwise comparisons of vitality scores among the groups after activity engagement indicated that the singing group was significantly higher in vitality compared to the cards group $(p=.038)$, but not compared to the band group $(p>.999)$. Similar to the pattern observed in the abovementioned PA measure, the band and cards groups did not differ in the post-test $(p=1)$. Pairwise comparisons of change over the course of the activity demonstrated a significant increase in vitality in the singing group $(p=.001)$ and a non-significant increase in vitality in the band group $(p=.448)$. The card group showed a non-significant trend to decrease in vitality $(p=.090)$. These results provide support for hypothesis 5 because the increase in vitality was greater after one session of singing than after one session of band or cards.

Turning to measures of social bonding (i.e., GIS and IOS), there were no differences in either measure before or after any group activity (all $p \mathrm{~s}>.5$ ). Pairwise comparisons of change (i.e., before vs. after) in each individual condition indicated that 


\section{WELL-BEING THROUGH SONG}

none of the groups increased significantly on the GIS, all $p \mathrm{~s}>.8$. The singing group did however increase significantly across session on the IOS $(p=.038)$ and the band demonstrated a non-significant trend in the increasing direction $(p=.157)$, while the cards group showed no change whatsoever $(p=1)$. Hypothesis 2 is partially supported by these findings because while one measure of social bonding (i.e., IOS) showed changes coinciding with the hypothesis, the other measure did not (i.e., GIS).

Table 3

Descriptive statistics for positive affect, social bonding, and vitality.

\begin{tabular}{lcclcccccc}
\hline Variable & \multicolumn{3}{c}{ Singing $M(S D)$} & \multicolumn{3}{c}{ Cards $M(S D)$} & \multicolumn{3}{c}{ Band $M(S D)$} \\
\hline \multirow{3}{*}{ Positive } & Before & After & Change & Before & After & Change & Before & After & Change \\
affect & 3.59 & 3.72 & .12 & 3.36 & 3.06 & -.31 & 3.60 & 3.27 & -.32 \\
Vitality & $(.73)$ & $(.75)$ & $(.55)$ & $(.71)$ & $(.72)$ & $(.48)$ & $(.73)$ & $(.86)$ & $(.39)$ \\
& 4.87 & 5.38 & .50 & 5.03 & 4.71 & -.31 & 5.24 & 5.37 & .13 \\
\multicolumn{1}{l}{ Social bonding } & $(1.18)$ & $(1.10)$ & $(1.01)$ & $(.95)$ & $(1.04)$ & $(.65)$ & $(1.28)$ & $(.93)$ & $(1.04)$ \\
IOS & 4.26 & 4.56 & .31 & 4.77 & 4.77 & .00 & 4.38 & 4.62 & .24 \\
& $(1.50)$ & $(1.59)$ & $(1.10)$ & $(1.37)$ & $(1.30)$ & $(.57)$ & $(1.29)$ & $(1.21)$ & $(.87)$ \\
GIS & 5.62 & 5.63 & .01 & 5.73 & 5.74 & .01 & 5.64 & 5.66 & .02 \\
& $(.71)$ & $(.71)$ & $(.58)$ & $(.65)$ & $(.58)$ & $(.50)$ & $(.66)$ & $(.65)$ & $(.62)$
\end{tabular}

Note. $N=94$ ( $\operatorname{singing} n=39$; cards $n=26$; band $n=29$ )

\section{Gender effects on well-being}

H4. In order to test whether women who are singers reported greater subjective well-being benefits than men who are singers, two independent samples t-tests were used. Given that the goal was to examine differences in subjective well-being among male and female singers in general and not differences across a single singing session, all participants regardless of group were coded as singers or non-singers. The coding was based on responses to group singing item of leisure activities measure (see Appendix $G$ ) because the focus of the present study was on benefits of group singing as opposed to singing in general. Using responses from the "group singing" item of the leisure 


\section{WELL-BEING THROUGH SONG}

activities measure participants across all conditions were coded as either singers (i.e., reported group singing once per month, once per week, a few times a week, or every day) or non-singers (i.e., never or do not enjoy). The data file was then split to explore the singers separately ( $n=51 ; 15$ males and 36 females). Although subjective well-being is comprised of PA, NA, and life satisfaction, the NA data was deemed unfit for inclusion in the gender analysis because of the previously discussed poor distribution (i.e., floor effect). While a non-parametric test was used as an alternative to the t-test for analysis of the perceived stress hypothesis (see below), it was not an option for this particular analysis because two of the three components of subjective well-being (i.e., PA and life satisfaction) were normally distributed, and combining or comparing results of parametric and non-parametric tests was thought to be inappropriate. Thus subjective well-being as an outcome for the test of the gender hypothesis consisted of only life satisfaction and PA.

Recall that life satisfaction was measured only once (before activity) as it was not likely to change over the course of a single session. PA measured before the activity was also used in order to capture a more trait like measures as opposed to state. In the first independent samples t-test gender served as the grouping variable and PA before activity was the test variable. Female singers were found to report slightly higher $\mathrm{PA}(M=3.61$, $S D=.74)$, than male singers $(M=3.41, S D=.45)$, however; this difference was not statistically significant $t(49)=-.97, p=.339$. Gender again served as the grouping variable in the second independent samples t-test and life satisfaction (i.e., mean score on the SWLS) was the test variable. Levene's test for equality of variances was violated in this analysis, $p=.001$. As a result of this violation, the $t$ statistic for equal variances not 


\section{WELL-BEING THROUGH SONG}

assumed was used. Although female singers were found to report slightly lower life satisfaction $(M=5.09, S D=1.20)$, as compared to male singers $(M=5.48, S D=.65)$, this difference was not statistically significant $t(45.205)=1.47, p=.147$. Taken together, these findings do not support hypothesis 4 . Women who are singers did not report greater subjective well-being benefits than men who are singers; in fact there was no significant gender difference on either the life satisfaction or PA components of subjective well-being. Moreover, the life satisfaction results suggest a non-significant trend for male singers to have higher life satisfaction than female singers, which is opposite to anticipated findings.

\section{Singing and perceived stress}

H6. The exploratory hypothesis that decrease in perceived stress would be greater after one session of singing than one session of each of the non-singing group activities was tested using a Kruskal-Wallis test. The aforementioned skewness and kurtosis present in the perceived stress data necessitated the use of this non-parametric test. The dependent variables used were perceived stress before activity and perceived stress after activity. The independent variable was condition (i.e., singing, band, and cards). There was no significant difference between participants in singing $(M d n=1.40)$, cards $(M d n=1.00)$, or band $(M d n=1.00)$, before engaging in the activity, $H(2)=3.41, p$ $=.182$. There was also no significant difference after engaging in the activity between the singing $(M d n=1.00)$, cards $(M d n=1.00)$, and band $(M d n=1.00), H(2)=.995, p=$ .610 . These results do not support hypothesis 6 . The non-singing controls (i.e., band and cards) demonstrated a floor effect in perceived stress before activity and thus could not get any lower in stress. While the singing group was slightly higher than the other 


\section{WELL-BEING THROUGH SONG}

groups prior to the activity this was not a significant difference. Therefore these results cannot provide evidence of how changes in perceived stress following singing compares to other group activities, namely band and card groups.

\section{Exploration of singing, PA, and social bonding mediation}

H3. Positive affect was anticipated to mediate the effect of singing on social bonding. Due to the highly exploratory nature of this hypothesis, mediation analyses were tested both with PA mediating the relationship between singing and social bonding, and with social bonding mediating the relationship between singing and PA. Group size was controlled for as a covariate in each model because size of singing group was previously found to impact single session changes in both social bonding and PA (i.e., changes in PA were greater in smaller as compared to larger choirs, whereas changes in IOS were greater in larger as compared to smaller choirs; Weinstein et al., 2016). The mediation hypotheses were tested using OLS regression. Both mediation analyses were performed using condition (singing vs. other conditions combined) as a categorical predictor. Change scores of PA and social bonding were computed following Pearce et al.'s (2015) method. In the first mediation model change in social bonding (after-before group activity) was the outcome variable and change in PA (after - before group activity) was the proposed mediator. Given that the IOS measure of social bonding was the only social bonding measure to demonstrate significant increases in the singing group, this measure was selected for the mediation model. Condition was first regressed on change in PA and was found to be a significant predictor, $b=.49, S E=.11, p<.001$. Next, regression of condition on change in social bonding, ignoring the mediator (i.e., change in PA) was found to be non-significant, $b=.35, S E=.21, p=.100$. Change in PA, 


\section{WELL-BEING THROUGH SONG}

controlling for condition, was subsequently found to positively trend towards being a significant predictor of change in social bonding, $b=.33, S E=.19, p=.087$. Finally, controlling for the mediator (i.e., change in PA), condition was not a significant predictor of change in social bonding, $b=.19, S E=.23, p=.417$, indicative of potential full mediation. Bootstrapping was used with 5000 samples to test the indirect effect. Findings indicated the indirect effect was significant, $b=.16, S E=.10,95 \% C I=.016$, .438 , thus providing partial support to hypothesis 3 .

In the second mediation model, change in PA was the outcome variable and change in social bonding was the proposed mediator. Condition (i.e., singing vs. nonsinging) again served as a categorical predictor. Regression of condition on change in PA, ignoring the mediator, was significant, $b=.49, S E=.11, p<.001$. Regression of condition on the mediator, change in social bonding, was not significant, $b=.35, S E=$ $.21, p=.100$. Results of the regression analysis also indicated that the mediator (i.e., change in social bonding), controlling for condition, showed a positive trend towards being a significant predictor of change in $\mathrm{PA}, b=.10, S E=.06, p=.087$. Upon controlling for the mediator (i.e., change in social bonding), condition was a very significant predictor of change in PA, $b=.46, S E=.11, p<.001$, which indicated full mediation was not present. Bootstrapping was again used with a sample of 5000 to test the indirect effect. There was no significant indirect effect found, $b=.03, S E=.03,95 \%$ $C I=-.004, .137$. These findings support the abovementioned notion that model 1 is appropriate and change in PA is mediating the relationship between conditions and change in social bonding and not vice versa as tested in model 2. 


\section{WELL-BEING THROUGH SONG}

\section{Indirect effects of PA on physical health}

H7. Positive affect was anticipated to mediate the effect of singing on selfreported physical health. This mediation model was again tested using regression. Group singing served as a continuous predictor in the model. Given that physical health is more of a stable characteristic and not likely to change over the course of a session, groups were collapsed across condition and coded according to reported participation in group singing (i.e., scale from $0-4$, anchored by "never" and "every day"). By recoding for group singing across all participants, the present study was able to examine whether being a singer (in a group context) might be associated with physical health (via PA), as opposed to whether a single group singing session impacts physical health. It is unlikely that identifiable changes from pre to post in a group singing activity would be found, especially without the use of more sensitive physiological measures. With this in mind, PA before activity was used as the mediator in the model because it was more likely to capture trait PA in contrast to the PA measures after the activity, which would be a more state-like measure. The outcome variable was self-reported physical health (i.e., health related quality of life as measured by mean score on the UQQoL). Group size was not controlled for in this particular model because singing was included as a continuous variable across all groups and the data collected only indicated whether or not individuals sang in a group and not the size of that group. The total effect as indicated by regression of group singing on self-reported physical health, ignoring the mediator (i.e., PA before group activity) was non-significant, but suggestive of a negative trend, $b=$ $.08, S E=.04, p=.082$. The regression of group singing on the mediator, PA before group activity, was also non-significant $b=.06, S E=.06, p=.338$. The mediator (i.e., 


\section{WELL-BEING THROUGH SONG}

PA before group activity), controlling for group singing, was a highly significant predictor of self-reported physical health, $b=.23, S E=.07, p=.001$. Controlling for the mediator (i.e., PA before group activity), group singing became a significant negative predictor of self-reported physical health, $b=-.09, S E=.04, p=.033$. Bootstrapping was used with a sample of 5000 to test the indirect effect. There was no significant indirect effect found, $b=.01, S E=.02,95 \% C I=-.015, .048$. These findings suggest a mediation effect is not present; however, there is evidence to suggest a suppression effect. As argued by Rucker, Preacher, Tormala, and Petty (2011) evidence of this suppression effect can be found in that inclusion of the proposed suppressor (PA) results in a value of the direct effect $\left(c^{\prime}=-.09\right)$ that is greater than the value of the total effect (c $=-.08)$. Moreover, when the sign of the indirect effect $(.01)$ is opposite to that of the total effect (-.08) the intervening variable (i.e., PA) is considered to be a suppressor (Rucker et al., 2011). In addition, inclusion of PA strengthened the previously non-significant relationship between singing and physical health, which further supports the notion that PA is a suppressor because it would be expected that inclusion would weaken this relationship had PA in fact been a mediator (Rucker et al., 2011). In the present study, PA (before) was found to be significantly positively correlated $(r=.30, p=.003)$ with health related quality of life and group singing was also positively correlated, although non-significantly, with PA $(r=.10, p=.34)$; however, group singing was negatively correlated $(r=-.18, p=.08)$ with health related quality of life.

\section{Dis cus sion}

The purpose of this study was to compare group singing to other group leisure activities of both musical and non-musical nature, in order to assess whether group 


\section{WELL-BEING THROUGH SONG}

singing possessed any unique benefits to well-being of community dwelling older adults beyond those of the other group activities. Moreover, this study explored whether these potential changes in well-being might occur over a single session of no more than a few hours. Potential mechanisms by which singing might impact well-being were also investigated. This study supports the idea that notable changes in well-being can occur over a single session of singing. Differences in changes in measures of PA and vitality were found to be the most distinguishable differences between the singing group and both the musical and non-musical control groups. While the GIS measure of social bonding demonstrated no significant difference among the three groups either before or after activity engagement, the IOS measure of social bonding differentiated between the groups, in that only the singing group showed a significant bonding increase over a single session. Exploration of mechanisms through mediation analysis suggests that PA might in fact serve as a pathway through which singing impacts social bonding as measured by the IOS.

\section{Changes in Well-being Meas ures}

The present study corroborates findings of previous studies that suggest singing may be associated with PA. While the singing, band, and card groups did not differ in levels of PA prior to engaging in their respective activities, the singing group did demonstrate higher PA than both the card and bands groups immediately after participating in the activity. Furthermore, it is important to understand the pattern in which PA changed in each of these groups across the session. The singing group showed a non-significant trend to increase in PA from before the activity to after; however, both the card and band groups demonstrated a significant decrease. It should be recognized 


\section{WELL-BEING THROUGH SONG}

that the decrease in PA in the control groups contributed to the significant differences among the groups, as the increase associated with singing was only a non-significant trend. In other words, while the hypothesis that singing would increase more than each of the non-singing activities was technically supported, it was not necessarily because the singing group itself increased much; instead, it was because the other groups did not increase at all (i.e., decreased). It is interesting to note that the differences were more pronounced when comparing singing against the non-musical control group as opposed to the musical control group (i.e., results indicated a non-significant trend of higher PA in singing as compared to band), yet when band and cards were compared to one another there was no significant difference. These findings refine those of Creech et al. (2013) who similarly found positive emotions (i.e., pleasure and control) were greater following musical as compared to non-musical engagement. In the present study, levels of positive emotions differed when musical engagement in the form of singing was compared to non-musical (i.e., cards), but not when musical engagement in the form of band was compared to non-musical engagement. These findings suggest not only is there a difference between musical as compared to non-musical activities on measures of positive emotions as Creech and colleagues (2013) suggest, but there is also a distinction between different types of musical activities. Although the difference in PA level between the musical activities of band and singing was less than that of singing and cards, it is nonetheless suggestive of a unique benefit of singing, beyond that of musical engagement in general, especially given that singing was the only group suggestive of an increase in PA, while the control groups both decreased. 


\section{WELL-BEING THROUGH SONG}

One possible explanation for the decrease in PA in the cards group was whether or not the participant was winning their games. During data collection many participants mentioned to the researcher the importance of having a good hand or winning their games on their mood. Given that each of the groups were provided identical questionnaires, with the exception of their particular group being identified in questions referencing the group (e.g., How long have you been participating in this band; Please circle the picture which best describes your relationship with your choir; I feel a bond with my card group), it was not possible to include a question pertaining to wins/losses for the bridge players. Had this information been available it may have provided some insight into why bridge players decreased in self-reported PA over the activity session.

The decrease in PA in the band group is a bit more challenging to interpret. Participating in a band requires a great deal of collaboration and cooperation, and sometimes this can be frustrating, which in turn might reduce positive emotions. For example, while collecting data the trumpet section of one of the bands kept coming in too early and starting on the wrong note resulting in the band as a whole having to start the song over. This was evidently somewhat frustrating to the other band members and may have reduced feelings of PA items such as interested, alert, and attentive due to the fact that they had to keep repeating the same part. Similar situations occurred in the other bands as well, which again might explain the decreased PA. Further support might be gathered from the results of Dunbar, Kaskatis, and MacDonald, Barra (2012), who found positive effects of active music engagement (i.e., increases in endorphins, which are thought to increase PA) were greatly reduced or completely diminished when the music was frequently interrupted (i.e., in the context of rehearsal). Along these same lines, the 


\section{WELL-BEING THROUGH SONG}

choirs were also interrupted in order to be redirected during rehearsals; however, the researcher does not recall observing these same signs of frustration in the singing groups as compared to the band. Perhaps because the criticism was directed more to the singing group as a whole, the singers may not have felt as disheartened and/or did not have a specific person (or people) to blame, while the band addressed more specific sections (e.g., trumpets) and even individual musicians.

The increase (albeit nonsignificant) in the singing group was anticipated and is in agreement with the findings of several other studies (Busch \& Gick, 2012; Kreutz et al., 2004; Kreutz, 2014; Unwin et al., 2002). Despite these similarities, it is worth noting the aforementioned studies have a number of limitations, thus reported increases following singing should be interpreted cautiously. By way of example, Unwin et al. (2002) measured positive changes in mood (using the P.O.M.S) and found a trend of larger effects in the singing group as compared to the listening group immediately after the activity; however, the comparison of active versus passive engagement may be considered flawed because previous studies (e.g., Dunbar et al., 2012) suggest passive listening does not induce heightened affect. Busch and Gick (2012) also noted significant increases in PA when measured immediately before and after a single rehearsal in a preexisting choir. However, Busch and Gick (2012) did not have a control group for comparison. Therefore, it might be the case that singing increases in the research because the comparisons are nonexistent (Busch \& Gick, 2012) or flawed (Kreutz 2004). Despite controlling for these limitations by including arguably more valid comparisons, there was still no significant increase in PA among the singing group. Further research is needed to clarify why PA did not increase significantly, but band and cards decreased significantly. 


\section{WELL-BEING THROUGH SONG}

In addition to measures of PA, vitality measures were also found to distinguish the singing group in the present study. Similarly to measures of PA, the three groups did not differ when vitality was measured before the activity; however, following the activity the singing group was found to report significantly higher vitality than the cards group. Moreover, there was no significant difference in vitality among the singing and band groups after engaging in their respective activities. When exploring the patterns of change over the session, it was found that the singing group was the only group to show a significant increase in vitality. While the band did demonstrate a slight increase, the change was non-significant. The cards group on the other hand, showed a non-significant trend to decrease in vitality from before the activity to after it. Past research suggests vitality might be an important variable to explore when studying singing and well-being (Gick, 2011); however, few studies have examined this variable in older adult samples.

Davidson et al. (2014) is one of the few studies that have looked at vitality in community dwelling older adults. Davidson and colleagues (2014) found that vitality significantly decreased in older adults following weekly 90-minute singing sessions over a span of 8 -weeks. The researchers suggested 8 weeks might have been too short a time span to see changes in well-being; however, in half that time (i.e., 4 weeks) Gick and Daugherty (2015) found a significant increase in vitality following a weekly singing intervention for asthma in a young adult sample. Furthermore, Busch and Gick (2012) also found a significant increase in vitality over the course of only a two-hour choir rehearsal in a sample of adults aged $28-80$ (average age of 56 years). Taken together, these studies provide evidence that contrasts with Davidson et al. (2014) and suggest significant vitality changes are certainly possible in a time span of less than 8 weeks, 


\section{WELL-BEING THROUGH SONG}

even less than a few hours. The present study provides further support for this as the singing group was found to significantly increase in vitality over a single session of around two hours.

As previously discussed, both the singing group and the band (albeit nonsignificantly) increased in vitality, while the card group showed a trend to decrease. One potential reason for the increase in band and singing, but not in cards is that both of the musical activities required more physical activity. As Busch and Gick (2012) noted, the physical aspects of singing might be captured by measures of vitality and somewhat explanatory of the increase. Arguably, the band group would also be physically engaged because much like singing, many instruments require careful control of breathing. On the other hand, some instruments (e.g., piano, guitar, and drums) although involving physical exertion do not require breathing control and perhaps for this reason the band showed a lesser increase than the choir where all members would need to focus on breathing. Playing cards does not involve much, if any physical engagement; thus it would be understandable for the card group to be lower on vitality, as seen in the present study.

In sum, the abovementioned findings on measures of PA and vitality further suggest that group singing may not only be beneficial for enhancing well-being, but may also provide unique benefits beyond general group leisure activities such as cards, or other group musical activities such as band. While participants significantly decreased in PA after playing cards or band practice, only participants who sang increased in PA, albeit non-significantly. Singing was also the only activity to be associated with significant increases in vitality. The results of the present study extend the findings of previous uncontrolled studies such as Busch and Gick (2012) and other more controlled 


\section{WELL-BEING THROUGH SONG}

studies (e.g., Kreutz, 2014) by further supporting the notion that singing may have the potential to improve both hedonic (i.e., PA) and eudaimonic (i.e., vitality) elements of well-being.

\section{Changes in Social Bonding}

The present study used both the GIS and IOS scales in order to explore changes in social bonding over the course of a single group activity session of singing, band, or cards. The decision to include two measures was related to personal concerns regarding older adults' understanding of the somewhat abstract pictorial IOS measure. In an attempt to minimize confusion related to this measure detailed instructions were developed which included visual examples of which item might be circled if one felt a high level of closeness with their group, as well as which item if they felt a low level of closeness to their group (see Appendix K). Despite the detailed instructions, many participants requested further clarification of how to respond during completion of the questionnaires. The inclusion of an additional social bonding measure (i.e., GIS) in the form of a text based scale supplemented data collected via the IOS and ensured an accurate depiction of the social bonding effects within these groups, in the event that the IOS measure produced largely missing data. Fortunately, the IOS measure had less than $5 \%$ missing data on both before and after measures respectively. Four out of one hundred and eleven total participants failed to complete the IOS measure before the activity and five participants failed to complete the IOS measure after the activity.

Results of the present study indicate that the singing, band, and card groups did not differ on either the GIS or IOS measures of social bonding prior to engaging in their respective activities. GIS measures after activity engagement also demonstrated no 


\section{WELL-BEING THROUGH SONG}

significant differences among the groups. Furthermore, there was practically no change at all in GIS scores over the course of the session. Turning to the IOS measure of social bonding, IOS scores remained unchanged in the card group, with the mean IOS score after the activity identical to those before the activity. IOS scores significantly increased in the singing group across the session and the band group demonstrated a non-significant trend to increase as well. These results are comparable to Pearce et al.'s (2015) study that found pre-post increases in social bonding in all groups, with higher increases in the singing group as compared to non-singing groups only at initial sessions; no group differences in social bonding changes occurred after initial sessions. The present results differ slightly in that control groups did not increase significantly from pre to post in social bonding. Pearce et al. (2015) posit that while the non-singing group may have had more opportunity for conversation, they "lacked a powerful means of bonding a whole class simultaneously" (p. 7). The effects seen in the present study may be partially explained by this same logic. The groups studied had been in existence for a while and were likely past stages of initial bonding, with the mean length of participation in each activity being greater than 5 years. That said, participants in each group were likely already somewhat stably bonded at the time of data collection. In this respect, the card group may have been the closest of the groups because they have had many opportunities to engage in close conversations and get to know each other while playing bridge, but did not show any change over the course of the session because there was no means to enhance feelings of social bonding. The band (trend to increase) and singing groups (significant increase) on the other hand had a means of enhancing feelings of closeness to the group as a whole because they were engaging in a collaborative synchronous activity. 


\section{WELL-BEING THROUGH SONG}

Pearce and colleagues (2015) propose, "group unity depends on behaviours that are synchronous and involve some muscular effort" (p. 7) and both singing and band involve these types of behaviours, while cards does not. Furthermore, singing might involve a greater degree of synchrony than band because participants use the same instrument (i.e., the human voice), while bands are made up of a variety of different instruments, which are often assigned different parts despite playing the same song. This difference in degree of synchrony may explain why the singing group significantly increased in social bonding over the course of a session, while the band only showed a trend to increase. The nature of the relationship between singing and social bonding is further discussed in the following section.

\section{Indirect Effects of Positive Affect}

Results of the present study suggest an indirect effect, indicating that increases in PA mediated the relationship between singing and increases in social bonding as measured by the IOS. Given that mechanisms have seldom been tested within this area of research, a second mediation model was also explored in which change in social bonding was tested as a proposed mediator of the relationship between condition and change in PA. Results of the second mediation model provided no evidence that change in social bonding was mediating the association between singing and change in PA, which further supports the initial model. Although Pearce and colleagues (2015) did not actually test this proposed mechanism in their study, they suggested that increases in PA leading to increases in social bonding might be a result of increased endorphins produced from physical engagement in a synchronous activity such as singing. Other studies such as Dunbar et al. (2012) and a review by Tarr, Launay, and Dunbar (2014) also provide 


\section{WELL-BEING THROUGH SONG}

supporting evidence for this line of reasoning. For example, Dunbar et al. (2014) compared across a single session a religious service involving mostly singing and clapping to another religious service with no music or singing (i.e., sermon with prayer) and found that the singing group had a significantly greater change from pre to post in pain threshold. In Dunbar et al. (2014) as well as other studies, pain threshold is used as a proxy measure for endorphins; thus by proxy the singing group showed a greater increase in endorphins. Future studies should strive to include more direct measures of endorphins (e.g., using a naloxone antagonist; Dunbar et al., 2014) in order to better explore whether the relationship between singing and PA might be mediated by these changes, and in turn whether this may influence social bonding. Suggestive evidence that neurohormonal processes [e.g., increases in oxytocin (Kreutz, 2014); increases in endorphins (Dunbar et al., 2014)] might be implicated in the association between singing and social bonding further underscores the earlier discussed importance of using a biopsychosocial framework when studying singing and well-being.

The present study did not include any physiological measures, but instead captured physical well-being through a measure of health related quality of life (i.e., the UQQoL), and hypothesized that PA might mediate the effect of singing on self-reported physical health (as quantified by the UQQoL). Results of the mediation model suggest that group singing was a non-significant predictor of a negative trend in physical health, and was also a non-significant predictor of $\mathrm{PA}$, which in turn was found to be a significant predictor of physical health. However, when controlling for the effects of PA, the previously non-significant (trend) negative effect of singing on physical health was rendered significant. Bootstrapping analyses indicated there was not an indirect effect, 


\section{WELL-BEING THROUGH SONG}

but instead, a possible suppression effect. Perhaps PA acts as a suppressor because another variable is responsible for the negative relationship between singing and health related quality of life. In other words, because PA was positively associated with both group singing and health, increases in PA associated with group singing were expected to predict increases in health related quality of life; however, this was not the case. If PA is in fact a suppressor as the abovementioned evidence suggests it begs the question as to what then is mediating the relationship between singing and poorer health related quality of life. These findings provide an avenue for future research to explore potential mechanisms through which being a singer (in a group context) might be associated with lower health related quality of life.

One potential explanation for the negative relationship between group singers and health related quality of life is the presence of a gender effect. In agreement with this reasoning, Cherry et al. (2013) found evidence of a gender effect on health related quality of life while studying social engagement and health among younger, older, and oldest-old adults. Cherry and colleagues (2013) found that women had significantly lower health related quality of life as compared to men. Moreover, this difference was found to increase with age as the difference was non-significant in the young adults $(21-59$ years $)$, significant in the older adults $(60-89$ years $)$ and most significant between men and women in the oldest-old $(90-97$ years). Upon exploring the gender breakdown of group singing across all participants in the present study non-singers were predominantly male $(60.5 \%)$, while singers (i.e., those who sang with a group once per month, once per week, a few times per week, or every day) were predominantly female (70.6\%). Taking the gender distribution of the present sample and the gender effects found by Cherry et al. 


\section{WELL-BEING THROUGH SONG}

(2013) into consideration, it is possible that singers showed a negative association with health related quality of life because the majority of the singers were females and females have lower levels of health related quality of life (Cherry et al., 2013). In respect to interpreting the negative relationship found between singing and health, it may not necessarily be that singing leads to lower health related quality of life, but rather that those who are lower in health related quality of life (i.e., women) are more likely to sing. Cherry and colleagues (2013) cite a number of reasons why older women might be lower in health related quality of life including lower body weight and strength, and greater discomfort with physical activity. With this in mind, perhaps singing is an activity that older women can continue well into late life, while more physical activities such as hiking or gardening might be given up as a result of physical declines.

\section{Gender Effects}

Gender effects have not been well examined in singing and well-being research. The present study contributed to addressing this gap in the literature by exploring whether there was a gender difference in subjective well-being among singers. Women who were singers were hypothesized to experience greater subjective well-being benefits than men who were singers. This hypothesis was based on the findings of Clift and Hancox (2001), which is one of the only known studies within this area of research to examine effects of gender. As previously noted subjective well-being is typically conceptualized by three components: life satisfaction, presence of positive mood, and absence of negative mood (Ryan \& Deci, 2001). Because of the unusable NA data, only the PA and life satisfaction components of subjective well-being were assessed, and no significant gender differences were found among the singers. The hypothesis was further 


\section{WELL-BEING THROUGH SONG}

rejected by the presence of a non-significant trend for male singers to have higher life satisfaction than females.

Although the results of the present study conflict with those of Clift and Hancox (2001), Clift and Hancox conceptualized well-being in a non-standardized way. That is, Clift and Hancox (2001) did not use validated or common measures of well-being such as the PANAS, but instead asked participants to rate their agreement with various statements about perceived benefits of singing (e.g., 'singing helps me to relax'). These statements were derived from a previous survey of a choir and divided into six multi-item components (e.g., well-being and relaxation; breathing and posture; social benefits; emotional benefits; spiritual benefits; heart and immune system). Moreover, Clift and Hancox's (2001) findings further lack generalizability as they come from a single choir that was in their late teens to early twenties and predominantly female. The variation in both in sample demographics and measures used greatly limits the comparability of the Clift and Hancox's findings to those of the present study. Furthermore, the small number of men (less than one third of the singers) in the present singing sample makes it difficult to reliably interpret any findings pertaining to gender effects. Despite challenges related to gender distribution, future studies should continue to explore possible gender differences when studying singing and health, as the results of the present study and Clift and Hancox (2001) are inconclusive in this respect.

\section{Changes in Perceived Stress}

Reviews such as those by Gick (2011) and Clift et al. (2008) suggest singing might be associated with stress reduction; however, the studies reviewed present evidence predominantly related to biological responses to stress (e.g., changes in cortisol). Few 


\section{WELL-BEING THROUGH SONG}

studies have actually considered how singing might change an individual's experience of stress (e.g., buffering effects). Moreover, the limited number of studies conducted with older adults and reviewed herein are inconclusive as to whether singing evokes a beneficial biological stress response in this population. As previously discussed, Kreutz et al. (2004) found no significant changes in cortisol levels after a group singing session, while Sakano et al. (2014) found a significant decrease in cortisol after a solo singing session. Furthermore, Kreutz and colleagues (2004) did not study older adults exclusively, despite the mean age of the sample being somewhat older (i.e., around 57 years). It is important for effects of singing on stress to be studied in older samples in order to determine whether findings of previous studies generalize to this group, especially because it has been suggested that age related changes occur in the stress response (Cavanaugh, Blanchard-Fields, \& Norris, 2008). The present study does not include physiological measures to capture changes in the biological stress response, but it does address some of the aforementioned limitations by not only using an older sample to explore the relationship between singing and stress, but also by considering individual experiences of stress. Based upon previous findings related to biological stress responses, it was hypothesized that decreases in perceived stress would be greater after one session of singing than one session of each of the non-singing group activities. Results indicated that levels of perceived stress did not differ significantly among the groups either before or after their respective activities. It is important to note that the non-singing activities demonstrated a floor effect and were already as low as possible prior to engaging in the activity. Therefore, no conclusions can be drawn in terms of how 


\section{WELL-BEING THROUGH SONG}

the association between singing and perceived stress differs from other non-singing activities (i.e., cards and band).

\section{Limitations and Stre ngths}

A number of limitations exist in the present study, particularly in respect to the study design. One such limitation is that the quasi-experimental design did not allow for random assignment. As previously discussed, limited use of random assignment is a problem across many studies of singing and well-being. The use of pre-existing groups was the best option for this particular study for a number of reasons. First of all, as Chong (2010) and Sakano et al. (2014) point out, not everyone enjoys singing and it could be especially distressing to assign participants to sing when they are not comfortable doing so. Given that the present study was interested in group identification and more specifically effects of social bonding it was also particularly important to consider Gick and Nicol's (2015) argument that random assignment could lead to both low level of group identification and even attrition because again not everyone likes to sing. As suggested by Weinstein et al. (2016), another benefit of using this more naturalistic design to study singing is that it provides "more valid insights into the realworld function of singing than do laboratory paradigms" (p. 156). Moreover, given the researcher's lack of musical ability, there was a definite feasibility issue in respect to facilitating singing and/or band groups for the purpose of this study. Finally, recruiting older adults can be somewhat challenging because unlike with undergraduate samples, there is not a pool from which participants can be drawn. Time constraints were also present and recruitment would likely have taken considerably longer had groups been created for the present study as opposed to being drawn from pre-existing activities. 


\section{WELL-BEING THROUGH SONG}

Another limitation in respect to study design and the use of ongoing groups was that there was a great deal of variability in length of participation. Unlike Pearce et al. (2015) who formed groups for the purpose of their study and were able to capture participants early in the activity, the present study captured both groups and individuals at various points. This variability was present both within groups (i.e., singing $.04-25$ years; cards $.42-50$ years; band $.13-25$ years) and between groups (see Table 2). The potential variability in length of participation was taken into consideration when designing the study and a question was added to the demographic measure to account for this; however, it appears some participants misinterpreted the question (i.e., How long have you been participating in this (choir/band/card) activity; for full item see Appendix F) and instead responded to how long they have played bridge in their lifetime as opposed to how long they have played with the particular group. As a result of this potential misinterpretation, it cannot be assumed that length of participation noted above was accurately captured. While it may have been beneficial to control for participation length, as studies such as Pearce et al. (2015) demonstrate stronger effects earlier in group formation, it was decided due to the probable inaccuracy of the data collected on participation length it would not be controlled for in any of the analyses.

The use of several different groups presents another potential limitation as a result of variation in the length of sessions. The singing sessions ranged from $1.5-2.5$ hours, with a mean session length of about 2 hours, while the band and cards sessions were all 2.5 hours long. Despite this variability, it is unlikely that differences in the length of sessions influenced the results. In support of this, Dunbar et al. (2012) had similar 


\section{WELL-BEING THROUGH SONG}

variability in their sample and argued past research has demonstrated engaging in an activity for as little as 15 minutes is enough to produce an effect if one is actually present.

In addition to variation in length, there was also some variation in the time of day that these sessions ran, and as a result the time of day data were collected. Most sessions were in the morning starting around 9 or $10 \mathrm{am}$, while others ran in the afternoon starting at around $1 \mathrm{pm}$, and some groups even ran in the evening starting after $7 \mathrm{pm}$. Taking this into consideration some responses may have been biased as a result of the time of day. By way of example, item 6 on the vitality scale asks participants to rate how true the statement "I feel energized" is for them at the present moment and one participant noted next to this statement "it's nearly 10 pm!" suggesting that time of day in which the measures were completed may have had some influence on responses. Moreover, data were collected from January - April, thus fluctuations in the weather might also have had a confounding effect on mood. For example, data collection had to be rescheduled with several of the bands because they were cancelled due to snowstorms. While some may argue this weather may have put participants in a poor mood, it could also be argued that those returning to band after a cancellation might be in a better mood than usual as they are excited to be back. One band member provided anecdotal evidence of this stating 'It's a shame you get us after we arrive, when I wake up and know I'm coming here I'm already in a good mood."

One further limitation of using pre-existing activity groups is that several groups were combined to make up one condition (e.g., five different singing groups combined to form the singing condition). As a result of this there is a potential nesting issue present in the data because of the presence of groups within groups. While more sophisticated 


\section{WELL-BEING THROUGH SONG}

statistical methods such as multi-level linear models have been used to control for potential confounding variables in studies with similar designs (e.g., Pearce et al., 2015), the complex nature of that type of analysis is beyond the scope of the present study. Despite this limitation, other attempts were made to control for confounding variables such as including group size as a covariate in the mediation analyses of social bonding.

There were also limitations present in the data itself, which in turn limited adequate testing of some of the hypotheses. One such issue was the gender distribution of the singers. Due to the fact that less than one-third of the singers were male, conclusions from analyses of the gender hypothesis are limited and should be interpreted cautiously with this in mind. Future studies should strive to use larger samples in an effort to improve upon this imbalance. Testing of the social bonding mediation (i.e., hypothesis 3) was limited by low variability in measures (i.e., low change in PA). Moreover, the GIS measure did not result in any significant changes among the groups, thus leading the IOS to serve as the social bonding measure.

Caveats aside, the present study also demonstrated a number of strengths. Although many researchers have suggested possible mechanisms of the singing and wellbeing relationship, very few of these mechanisms have actually been tested (Gick, 2011). Regardless of the findings obtained, the present study represents an important development in singing research because it made an attempt to test mechanisms as opposed to solely speculating about the possibilities. Another strength of this study is the use of popular psychometrically valid measures, thus allowing for better comparability of results to future studies. The use of reliable and valid quantitative measures also offers strength in that it allows the present study to contribute empirical evidence of the benefits 


\section{WELL-BEING THROUGH SONG}

of singing on well-being, thus building upon past qualitative studies which were only descriptive. Clift et al. (2008) argued singing and well-being research was lacking progressive development, thus by not only building upon past qualitative findings, but also extending upon past quantitative studies (e.g., Creech et al., 2013; Pearce et al., 2015) the present study is making strides towards progressive development. For example, Pearce and colleagues (2015) suggested PA might be mediating the relationship between singing and social bonding but did not test this; thus the present study extends upon Pearce et al.'s (2015) study by providing evidence that PA may in fact mediate the relationship between singing and social bonding. Creech et al.'s (2013) study was also further developed by the present study because evidence was found that not only is active music engagement beneficial for well-being as Creech and colleagues suggested (2013), but also different musical activities are associated in unique ways with well-being variables (e.g., singing associated with a trend to increase in PA, while instrumental band associated with a significant decrease).

In addition to the abovementioned strengths, the present study also showed strength in the use of appropriate controls. Many of the studies on singing and well-being have either not used a control group at all or used somewhat flawed comparisons (e.g., listening or usual activities control). Thus, the two control groups used in the present study were a strength because not only did they allow for comparison of a variety of different leisure activities, but they also allowed for exploration of potential differences between singing and another musical activity. 


\section{WELL-BEING THROUGH SONG}

\section{Future Research}

Future studies of singing and well-being should continue to use a biopsychosocial framework. As illustrated by the findings in the present study effects of singing might result from interaction between psychological and social factors (e.g., singing influences social bonding through PA) and though physiological measures were not included in the present study, biological factors may also be implicated in such interactions. As Kreutz (2014) suggests biological responses such as increases in hormones like oxytocin might facilitate social bonding.

As previously discussed, researchers should continue to strive to use more reliable and valid quantitative measures in this area of research in order to move past the highly descriptive nature of this field. Moreover, researchers should ensure they are using measures that are validated for the specific population being studied. The present study used many measures that had been validated for older samples; however, the IOS was not and the older participants found it challenging to understand despite the lengthy and detailed instructions. That being said, future research in this area should either pilot measures on an older sample prior to use or use measures with known validation for older people. Along these same lines, newly developed measures such as the leisure activity measure used in the present study [adapted from Pressman et al.'s (2009) PEAT] should also be pilot tested to prior to data collection to again capture any issues.

Another suggestion for future studies would be to further explore the association between social bonding and singing as compared to other group activities with shared goals. While some might argue the cards group in the present study had the shared goal of playing bridge, Pearce et al. (2015) suggest the synchronous component of certain 


\section{WELL-BEING THROUGH SONG}

group activities such as choir or band might play an important role in social bonding. One example of a control group that might be useful in further exploration of the social bonding effects of group activities as compared to group singing is a group dance class because it integrates that synchronous component. Another activity that might be an interesting comparison is a group working on a quilt together.

Future research should also explore samples that are more demographically diverse, particularly in terms of SES. The present study included a sample that was for the most part well educated, financially comfortable, and Caucasian; as such it is unclear how these findings might generalize to older adults of other races and lower SES. Pressman et al. (2009) found that females who were Caucasian, higher income, and more educated participated more frequently in leisure activities which in turn was associated with numerous psychological benefits (e.g., greater positive affect, life satisfaction, and purpose; lower negative affect and fewer depressive symptoms). That said, future studies might want to control for SES in order to better isolate the benefits related to singing itself. Although attempts were made in the present study to recruit a singing group from a seniors' center in a lower income area, that particular center was not interested in participating.

\section{Conclusion}

The present study built upon existing research to provide evidence suggesting group singing may be beneficial for the well-being of older adults. Singing demonstrated some unique benefits beyond those associated with other leisure activities. In comparison to both musical (i.e., band) and non-musical (i.e., cards) control group activities singing demonstrated a unique trend to increase in PA while controls decreased; 


\section{WELL-BEING THROUGH SONG}

singing also demonstrated significant increases in vitality. A single session of about two hours was sufficient to produce these changes. The present study extends past research by having a musical comparison group and, importantly, by testing mechanisms of the relationship between singing and well-being. Positive affect was identified as an important variable in relation to changes in singing and well-being. While PA did not mediate the relation between singing and health related quality of life, it did mediate the association between singing and social bonding. The present study serves as an important stepping-stone for future singing and well-being research, which should continue to conduct more controlled studies and further exploration of mechanisms of singing and well-being. Moreover, the findings of this study support the notion that group singing may be a useful activity for older adults to not only maintain their social engagement, but also enhance their well-being. These findings may be implicated in the development of future health promotion and leisure policies for older adults. Group singing is an accessible, inexpensive activity (i.e., all you need is a voice and people to sing with) that appears to be beneficial for the psychological, social, and physical wellbeing of older adults. In closing, these findings highlight the importance of recreational facilities continuing to offer such programs and these facilities should strive to frame programs in a way that is accessible to older adults and encourages participation. 


\section{WELL-BEING THROUGH SONG}

\section{References}

Allison, P. (2014). Listwise Deletion: It's NOT Evil. Retrieved from $\underline{\text { http://statisticalhorizons.com/listw ise-de letion-its-not-evil. }}$

Aron, A., Aron, E. N., \& Smollan, D. (1992). Inclusion of other in the self scale and the structure of interpersonal closeness. Journal of Personality and Social Psychology, 63(4), 596-612. doi:10.1037//0022-3514.63.4.596

Bennett, K. M. (2002). Low level social engagement as a precursor of mortality among people in later life. Age and Ageing, 31, 165-168.

Busch, S. \& Gick, M. (2012). A quantitative study of choral singing and psychological well being. Canadian Journal of Music Therapy, 18, 45-61.

Buz, J., Pérez-Arechaederra, D., Fernández-Pulido, R., \& Urchaga, D. (2015). Factorial structure and measurement invariance of the PANAS in Spanish older adults. The Spanish Journal of Psychology, 18. doi:10.1017/sjp.2015.6

Cavanaugh, J. C., Blanchard-Fields, F., \& Norris, J. E. (2008). Adult Development and Aging, First Canadian Edition. Toronto, ON: Nelson Education Ltd.

Chappell, N. L., \& Hollander, M. (2013). Aging in Canada. Toronto, ON: Oxford University Press.

Cherry, K. E., Walker, E. J., Brown, J. S., Volaufova, J., LaMotte, L. R., Welsh, D. A. . . Frisard, M. I. (2013). Social engagement and health in younger, older, and oldest old adults in the Louisiana healthy aging study. Journal of Applied Gerontology, 32, 51-75. doi:10.1177/0733464811409034

Chong, H. J. (2010). Do we all enjoy singing? A content analysis of non-vocalists' attitudes towards singing. The Arts in Psychotherapy, 37, 120-124. 


\section{WELL-BEING THROUGH SONG}

Clift S. \& Hancox G. (2001) The perceived benefits of singing: findings from preliminary surveys of a university college choral society. The Journal of the Royal Society for the Promotion of Health, 121, 248-256.

Clift, S., Hancox, G., Staricoff, R., \& Whitmore, C. (2008). Singing and health: A systematic mapping and review of non-clinical research. Sidney de Haan Research Centre for Arts and Health: Canterbury Christ Church University. Retrieved from http://www.creativityaustralia.org.au/wp content/uploads/2012/05/Report-5-SystematicMapping-and-Review.pdf

Clift S., Nicol J., Raisbeck M., Whitmore C., Morrison I. (2010) Group singing, wellbeing and health: a systematic mapping of research evidence. UNESCO Observatory Multi Disciplinary Research in the Arts e-Journal, 2, 1-25.

Retrieved from $\underline{\text { http://education.unimelb.edu.au/ data/assets/pdf file/0007/1105927/cliftpaper.pdf }}$

Cohen, G. D., Perstein, S., Chapline, J., Kelly, J., Firth, K. M., \& Simmens, S. (2006). The impact of professionally conducted cultural programs on the physical health, mental health, and social functioning of older adults. The Gerontologist, 46, 726773. Retrieved from http://gerontologist. oxfordjournals.org/

Cohen, G. D., Perlstein, S., Chapline, J., Kelly, J., Firth, K. M., \& Simmens, S. (2007). The impact of professionally conducted cultural programs on the physical health, mental health, and social functioning of older Adults-2-year results. Journal of Aging, Humanities, and the Arts, 1(1-2), 5-22. doi:10.1080/19325610701410791 


\section{WELL-BEING THROUGH SONG}

Creech, A., Hallam, S., Varvarigou, M., McQueen, H., \& Gaunt, H. (2013). Active music making: a route to enhanced subjective well-being among older people. Perspectives in Public Health, 133, 36-43. doi: 10.1177/1757913912466950

Davidson, J. W., McNamara, B., Rosenwax, L., Lange, A., Jenkins, S., \& Lewin, G. (2014). Evaluating the potential of group singing to enhance the well-being of older people. Australasian Journal on Ageing, 33,99-104. doi:10.1111/j.1741 6612.2012.00645.x

Deci, E.L., \& Ryan, R.M. (2000). The 'what' and 'why' of goal pursuits: Human needs and the self determination of behavior. Psychological Inquiry, 11, 227-268.

Diener, E., Emmons, R. A., Larsen, R. J., \& Griffin, S. (1985). The satisfaction with life scale. Journal of Personality Assessment, 49, 71-75. doi:10.1207/s 15327752jpa4901_13

Dunbar, R. I. M., Kaskatis, K., MacDonald, I., \& Barra, V. (2012). Performance of music elevates pain threshold and positive affect: Implications for the evolutionary function of music. Evolutionary Psychology : An International Journal of Evolutionary Approaches to Psychology and Behavior, 10(4), 688-702. doi:10.1177/147470491201000403

Engel, G. L. (1977). The need for a new medical model: A challenge for biomedicine. Science, 196, 129-136.

Field, A. (2005). Discovering statistics using SPSS ( $2^{\text {nd }}$ ed. $)$. Los Angeles: Sage Publications Limited.

Gick, M. L. (2011). Singing, health and well-being: A health psychologist's review. Psychomusicology, 21(1/2), 176-207. 


\section{WELL-BEING THROUGH SONG}

Gick, M. L., \& Daugherty, C. (2015). Changes in spirometry, quality of life and well being in persons with asthma following singing, diaphragmatic breathing, and singing and diaphragmatic breathing: A pilot study. Music \& Medicine 7(4), 40 49.

Gick, M. L., \& Nicol, J. J. (2015). Singing for respiratory health: Theory, evidence and challenges. Health Promotion International, 1-10. doi:10.1093/heapro/dav013

Gilmour, H. (2012). Social participation and the health and well-being of Canadian seniors. Health Reports, 23(4). Statistics Canada Catalogue no. 82-003-XPE. Ottawa: Statistics Canada.

Gilmour, H., \& Park, J. (2006). Dependency, chronic conditions and pain in seniors. Health Reports, 16, 21-31. Statistics Canada Catalogue no. 82-003-X. Ottawa: Statistics Canada.

Hayes, A. F. (2016). The PROCESS macro for SPSS and SAS. Retrieved from http://processmacro.org/index.html.

Hayes, A. F. (2013). Introduction to Mediation, Moderation, and Conditional Process Analysis: A Regression-Based Approach. New York: The Guilford Press. Retrieved from http://www.eblib.com

Hayes, A. F. (2009). Beyond Baron and Kenny: Statistical mediation analysis in the new millennium. Communication Monographs, 76(4), 408-420. doi:10.1080/03637750903310360

Health Canada, Division of Aging and Seniors. (2002). Physical activity and older adults. Ottawa: Minister of Public Works and Government Services Canada 


\section{WELL-BEING THROUGH SONG}

Henwood, T. R., \& Bartlett, H. P. (2008). Measuring the impact of increased exercise on quality of life in older adults: The UQQoL, a new instrument. European Journal of Ageing, 5(3), 241-252. doi:10.1007/s10433-008-0084-6

Hillman, S. (2002). Participatory singing for older people: A perception of benefit. Health Education, 102,163-171. doi:10.1108/09654280210434237

Houston, D., McKee, K., Carroll, L., \& Marsh, H. (1998). Using humour to promote psychological wellbeing in residential homes for older people. Aging \& Mental Health,2, 328-332.

Johnson, J. K., Louhivuori, J., Stewart, A. L., Tolvanen, A., Ross, L., \& Era, P. (2013). Quality of life (QOL) of older adult community choral singers in Finland. International Psychogeriatrics / IPA, 25, 1055. doi:10.1017/S1041610213000422

Kercher, K. (1992). Assessing subjective well-being in the old-old. Research on Aging, 14(2), 131-168. doi: 10.1177/0164027592142001

Kim, H.Y. (2013). Statistical notes for clinical researchers: assessing normal distribution using skewness and kurtosis. Restorative Dentistry \& Endodontics, 38, 52-54. http://doi.org/10.5395/rde.2013.38.1.52

Kreutz, G., Bongard, S., Rohrmann, S., Hodapp, V., \& Grebe, D. (2004). Effects of choir singing or listening on secretory immunoglobulin A, cortisol, and emotional state. Journal of Behavioral Medicine, 27, 623-635. doi:10.1007/s10865-004-0006-9

Kreutz, G. (2014). Does Singing Facilitate Social Bonding? Music \& Medicine, 6, 51-60.

Kuykendall, L., Tay, L., \& Ng, V. (2015). Leisure engagement and subjective well-being: A meta-analysis. Psychological Bulletin, 141(2), 364-403. doi:10.1037/a0038508 


\section{WELL-BEING THROUGH SONG}

McNair, D. M. \& Droppleman, L. F. (1981). Profile of Mood States. San Diego, California: Educational and Industrial Service.

National Seniors Council (2014, November 21). Report on the Social Isolation of Seniors. Retrieved from http://www.seniorscouncil.gc.ca/eng/research_publications/social_is olation/page5

Noice, T., Noice, H., \& Kramer, A. F. (2014). Participatory arts for older adults: A review of benefits and challenges. The Gerontologist, 54, 741 . doi:10.1093/geront/gnt138

Pearce, E., Launay, J., \& Dunbar, R.I.M. (2015). The ice-breaker effect: singing mediates fast social bonding. Royal Society Open Science, 2: 150-221. doi:10.1098/rs os. 150221

Pressman, S. D., \& Cohen, S. (2005). Does positive affect influence health? Psychological Bulletin, 131(6), 925-971. doi:10.1037/0033-2909.131.6.925

Pressman, S. D., Matthews, K. A., Cohen, S., Martire, L. M., Scheier, M., Baum, A., \& Schulz, R. (2009). Association of enjoyable leisure activities with psychological and physical well-being. Psychosomatic medicine, 71(7), 725.

Rucker, D. D., Preacher, K. J., Tormala, Z. L., \& Petty, R. E. (2011). Mediation analysis in social psychology: Current practices and new recommendations: Mediation analysis in social psychology. Social and Personality Psychology Compass, 5(6), 359-371. doi:10.1111/j.1751-9004.2011.00355.x

Ryan, R. M., \& Deci, E. L. (2001). On happiness and human potentials: A review of research on hedonic and eudaimonic well-being. Annual Review of Psychology, 52,141 . 


\section{WELL-BEING THROUGH SONG}

Ryan, R.M. \& Frederick, C. (1997). On energy, personality and health: Subjective vitality as a dynamic reflection of well-being. Journal of Personality, 65, 529-565.

Sakano, K., Ryo, K., Tamaki, Y., Nakayama, R., Hasaka, A., Takahashi, A., .. . Saito, I. (2014). Possible benefits of singing to the mental and physical condition of the elderly. BioPsychoSocial Medicine, 8, 11. doi:10.1186/1751-0759-8-11

Sani, F., Madhok, V., Norbury, M., Dugard, P., \& Wakefield, J. R. H. (2015). Greater number of group identifications is associated with healthier behaviour: Evidence from a Scottish community sample. British Journal of Health Psychology, 20(3), 466-481. doi:10.1111/bjhp. 12119

Skingley, A., \& Bungay, H. (2010). The Silver Song Club project: Singing to promote the health of older people. British Journal of Community Nursing, 15, 135-140.

Statistics Canada.(2015). Annual Demographic Estimates: Canada, Provinces and Territories. Statistics Canada Catalogue no. 91-215-X. Ottawa: Statistics Canada.

Tabachnick, B.G., \& Fidell, L.S. (2007). Using multivariate statistics (5th ed.). Boston, MA: Pearson Education Limited.

Tarr, B., Launay, J., \& Dunbar, R. I. M. (2014). Music and social bonding: "self-other" merging and neurohormonal mechanisms. Frontiers in Psychology, 5, 1-10. (doi:10.3389/ fpsyg.2014.01096)

Unwin, M. M., Kenny, D. T., \& Davis, P. J. (2002). The effects of group singing on mood. Psychology of Music, 30, 175-185. doi:10.1177/0305735602302004

Ware, J.E. Jr., \& Sherbourne, C.D. (1992). The MOS 36-item short-form health survey (SF-36). I. Conceptual framework and item selection. Med Care, 30(6) 473-483. 


\section{WELL-BEING THROUGH SONG}

Watson, D., Clark, L. A., \& Tellegen, A. (1988). Development and validation of brief measures of positive and negative affect: The PANAS scales. J. Pers. Soc. Psychol. 54: 1063-1070.

Weinstein, D., Launay, J., Pearce, E., Dunbar, R. I. M., \& Stewart, L. (2016). Singing and social bonding: Changes in connectivity and pain threshold as a function of group size. Evolution and Human Behavior, 37(2), 152-158.

doi:10.1016/j.evolhumbehav.2015.10.002

Wise, G. W., Hartmann, D. J., \& Fisher, B. J. (1992). Exploration of the relationship between choral singing and successful aging. Psychological Reports, 70, 11751183. doi:10.2466/pr0.1992.70.3c.1175 


\section{WELL-BEING THROUGH SONG}

Appendix A

\section{Recruitment Script}

Hello, my name is Laura Thompson and I am a Masters student in psychology at Carleton University. I am doing research under the supervision of Dr. Mary Gick that looks at older adults and the leisure activities they engage in and the effects this might have on well-being. I am here today to invite you to participate in this research. I am looking for volunteer participants to complete paper-and-pencil questionnaires immediately before and after engaging in activities such as this (choir/band/card group). The questionnaires will take approximately $15-20$ minutes to complete before your (choir/band rehearsal or game) and $15-20$ minutes after. Participation is entirely voluntary and no incentives will be provided. To be able to participate in the study, you should feel that you are able to read and write comfortably in English. You would be free to withdraw from the study at anytime, for any reason, up until one month after your completion and any associated data would be destroyed. All information collected from the questionnaires will be kept confidential and anonymous. I would also be happy to provide anyone interested with more information about the study after it has been completed. This ethics protocol for this project was reviewed by the Carleton University Research Ethics Board-B (Protocol \#15-277; expiry 08-31-2016), which provided clearance to carry out the research. I will return at (specify date during the next month and time before activity) and anyone interested in participating can complete a questionnaire at that time.

Does anyone have any questions? (Answers any questions). Thank you for your time and I will see you again on (date) 
Appendix B

\section{Carleton \\ Canada's Capital University}

\section{Informed Consent Form}

Title: Leisure Engagement and Well-being in Older Adults

Purpose of Study: This study aims to gain a better understanding of the potential benefits of leisure engagement in older adults. Specifically, benefits to psychological, social, and physical well-being will be examined.

Task Requirements: If you agree to participate in this study, you will be asked to complete two questionnaires. The first questionnaire will be completed just before engaging in your regularly scheduled leisure activity and the second will be completed immediately after your activity. These questionnaires will contain various measures of well-being and will ask various questions related to leisure activities you engage in. You will also be asked to provide some basic demographic information (e.g., age, gender, marital status) and questions about life satisfaction and quality of life. Both questionnaires should take approximately $15-20$ minutes each to complete.

Potential Benefits: There are no direct benefits to you as a participant; however, the results of this study might benefit both society and the research community through learning more about the potential health and well-being benefits of various leisure activities.

Potential Risks or Discomfort: You are free to skip any questions you do not want to answer for any reason. You are also free to withdraw your participation from the study at any point up until one month after completion.

Confide ntiality: All data collected will be kept confidential and anonymous. Your identity will not be disclosed in any reports of the study and all results published will be based on summary data. You will be assigned an anonymous identification number to be used on all questionnaires. This anonymous identification number and your name will only be linked on a password-protected document stored separately from all other materials and will only be accessible to the researcher and academic supervisor. This document will allow associated data to be destroyed should you wish to withdraw from the study after completion.

All data will be stored securely and anonymously, and kept for 5 years as per APA guidelines. After 5 years, data will be destroyed in a secure manner (i.e., hard copies shredded and electronic data erased). Electronic anonymously coded data will be stored on a password-protected computer. A backup copy of the anonymously coded data will also be stored on Dropbox. Hard copies of the anonymous questionnaires will be stored 


\section{WELL-BEING THROUGH SONG}

in a locked cabinet on Carleton University campus. Signed consent forms will be stored separately from all data and kept in a locked cabinet at Carleton University. Raw data will be available only to the researcher and her academic supervisor. Results of data analyses and anonymously coded data may be shared with trusted professional colleagues.

Voluntary Nature of Study/Right to Withdraw: Your participation in this study is entirely voluntary and no incentives will be provided. As previously noted, you may choose not to answer any questions for any reason. At any time during your completion of the study and up until one month after, you may let the researcher (or research supervisor) know if you wish to withdraw from the study and all data will be promptly destroyed. You may withdraw your participation for any reason.

Contacts for Questions or Concerns : You are welcome to contact the researcher to request an electronic copy of the research after the project has been completed. If you have questions, comments, or concerns about this study, you may contact Laura Thompson (Lead Researcher), at: laura.thompson3@,carleton.ca or Dr. Mary Gick (Academic Supervisor), at: mary.gick@,carleton.ca or 613-520-2600, ext. 1727.

This research has been cleared by Carleton University Research Ethics Board-B (Protocol \#15-277; expiry 08-31-2016). Should anyone have ethical concerns with the study they may contact Dr. Shelley Brown, Chair, Carleton University Research Ethics Board-B, via email at Shelley.Brown@,carleton.ca, or via telephone at 613-520-2500 ext. 1505. Participants may also contact the Carleton University Research Office directly at ethics@,carleton.ca.

\section{Participant Consent:}

I , have read the above description and choose to participate in a study on leisure engagement. This study aims to gain a better understanding of the potential benefits of leisure engagement in older adults. The researcher for this study is Laura Thomps on in the Carleton University Psychology department. She is working under the supervision of Dr. Mary Gick, associate professor in Psychology at Carleton University.

Signature of participant

Date

Signature of researcher

Date 
Appendix C

\section{Carleton}

\section{Debriefing}

\section{What are we trying to learn in this re search?}

Past research has suggested that leisure activities may be beneficial for adults. In particular, singing is an activity that may offer many potential well-being benefits for older adults; however, it is unclear whether singing might provide any additional benefits above those associated with general leisure engagement. As such, the main goal of this study is to compare group singing to other leisure activities in order to explore whether singing offers any unique benefits above and beyond those associated with leisure engagement alone. We selected both musical (i.e., band) and non-musical (i.e., cards) control activities in order to further assess whether benefits are associated with active music engagement or whether singing possesses unique benefits. The second goal of this study is to attempt to understand why these benefits might occur. The third goal of this study is to explore whether benefits can occur over a single activity session.

\section{Why is this important to scientis ts or the general public?}

This is important to scientists because previous studies have not offered strong comparisons (if any) of singing and other activities and there is a lack of understanding in the current research of why these benefits might occur. This is important to the general public because the findings may inform us about ways to enhance the quality of life, health, and well-being of our older population.

\section{What are our hypotheses and predictions?}

Based on previous research, we predict that those in the singing group will show greater increases in measures of psychological well-being (e.g., feelings of energy and positive mood) and identification with the other singers in the group over a single activity session than those in the other groups (band and cards). The singing group is also 


\section{WELL-BEING THROUGH SONG}

anticipated to have a greater decrease in perceived stress over a single activity session compared to the other groups. Women are expected to experience greater well-being benefits after one session of singing than men.

\section{Where can I learn more?}

Singing's secret power: The Ice-breaker Effect:

http://www.ox.ac.uk/news/2015-10-28-s inging's-secret-power-ice-breaker-effect-1

Singing and Health: Summary of a Systematic Mapping and Review of Non-Clinical Research:

http://www.creativityaustralia.org.au/wp-content/uploads/2012/05/Report-5-SystematicMapping-and-Review.pdf

\section{Is the re anything I can do if I found this experiment to be e motionally upsetting?}

If you experience any distress or anxiety as a result of your participation, you are welcome to contact the Carleton University Health and Counselling Services at: 613-5206674, or the Distress Centre of Ottawa and Region at 613-238-3311 (http://www.dcottawa.on.ca).

\section{What if I have questions later?}

If you have questions, comments, or concerns about this study, you may contact Laura Thompson (Lead Researcher), at: laura.thompson3@,carleton.ca or Dr. Mary Gick (Academic Supervisor), at: mary.gick@,carleton.ca or 613-520-2600 x 1727.

Should you have any ethical concerns about this research, please contact the Carleton University Research Ethics Board (613-520-2517; ethics@carleton.ca) or Dr. Shelley Brown (Chair, Carleton University Research Ethics Board-B; shelley_brown@carleton.ca; 613-520-2600, ext. 1505). This study has received clearance by the Carleton University Research Ethics Board-B (Protocol \#15-277; expiry 08-312016). 
Appendix D

\section{Satis faction with Life Scale}

Below are five statements that you may agree or disagree with. Using the 1 - 7 scale below, indicate your agreement with each item by placing the appropriate number on the line preceding that item. Please be open and honest in your responding.

1. In most ways my life is close to my ideal.

\begin{tabular}{|c|c|c|c|c|c|c|}
\hline 1 & 2 & 3 & 4 & 5 & 6 & 7 \\
\hline $\begin{array}{l}\text { Strongly } \\
\text { disagree }\end{array}$ & Disagree & $\begin{array}{l}\text { Slightly } \\
\text { disagree }\end{array}$ & $\begin{array}{c}\text { Neither } \\
\text { agree nor } \\
\text { disagree }\end{array}$ & $\begin{array}{c}\text { Slightly } \\
\text { agree }\end{array}$ & Agree & $\begin{array}{c}\text { Strongly } \\
\text { agree }\end{array}$ \\
\hline
\end{tabular}

2. The conditions of my life are excellent.

$\begin{array}{ccccccc}\mathbf{1} & \mathbf{2} & \mathbf{3} & \mathbf{4} & \mathbf{5} & \mathbf{6} & \mathbf{7} \\ \text { Strongly } & \text { Disagree } & \text { Slightly } & \text { Neither } & \text { Slightly } \\ \text { disagree } & & \text { disagree } & \begin{array}{c}\text { agree nor } \\ \text { disagree }\end{array} & \text { agree } & & \begin{array}{c}\text { Strongly } \\ \text { agree }\end{array} \\ & & & & & \end{array}$

3. I am satisfied with my life.

$\begin{array}{ccccccc}\mathbf{1} & \mathbf{2} & \mathbf{3} & \mathbf{4} & \mathbf{5} & \mathbf{6} & \mathbf{7} \\ \begin{array}{l}\text { Strongly } \\ \text { disagree }\end{array} & \text { Disagree } & \begin{array}{c}\text { Slightly } \\ \text { disagree }\end{array} & \begin{array}{c}\text { Neither } \\ \text { agree nor } \\ \text { disagree }\end{array} & \begin{array}{c}\text { Slightly } \\ \text { agree }\end{array} & \begin{array}{c}\text { Agree } \\ \text { Strongly } \\ \text { agree }\end{array}\end{array}$

4. So far I have gotten the important things I want in life.

$\begin{array}{ccccccc}\mathbf{1} & \mathbf{2} & \mathbf{3} & \mathbf{4} & \mathbf{5} & \mathbf{6} & \mathbf{7} \\ \begin{array}{c}\text { Strongly } \\ \text { disagree }\end{array} & \text { Disagree } & \begin{array}{c}\text { Slightly } \\ \text { disagree }\end{array} & \begin{array}{c}\text { Neither } \\ \text { agree nor } \\ \text { disagree }\end{array} & \begin{array}{c}\text { Slightly } \\ \text { agree }\end{array} & \text { Agree } & \begin{array}{c}\text { Strongly } \\ \text { agree }\end{array} \\ & & & & & \end{array}$

5. If I could live my life over, I would change almost nothing.

$\begin{array}{ccccccc}\mathbf{1} & \mathbf{2} & \mathbf{3} & \mathbf{4} & \mathbf{5} & \mathbf{6} & \mathbf{7} \\ \begin{array}{c}\text { Strongly } \\ \text { disagree }\end{array} & \text { Disagree } & \begin{array}{c}\text { Slightly } \\ \text { disagree }\end{array} & \begin{array}{c}\text { Neither } \\ \text { agree nor } \\ \text { disagree }\end{array} & \begin{array}{c}\text { Slightly } \\ \text { agree }\end{array} & \text { Agree } & \begin{array}{c}\text { Strongly } \\ \text { agree }\end{array} \\ & & & & & \end{array}$




\section{University of Que ens land Quality of Life Instrume nt}

This questionnaire aims to assess your current quality of life, physical health, and social wellbeing. The questions are concerned with both the mental and physical aspects of your day-to-day life. Please answer each question by placing a circle around one answer which best describes you. Example:

I have no problem with household tasks.

$\begin{array}{cccc}\text { MOST OFTEN } & \text { TRUE HALF } & \text { ALMOST } & \text { NEVER TRUE } \\ & \text { TRUE } & \text { THE TIME } & \text { NEVER TRUE }\end{array}$

You would circle "TRUE" if you experience no restrictions within your own home.

But if required assistance for the bulk of the household tasks (e.g. laundry, cleaning, bed making) then you would circle "ALMOST NEVER TRUE'.

1. My physical ability concerns me.

TRUE

MOST OFTEN

TRUE
TRUE HALF

THE TIME
ALMOST
NEVER TRUE

NEVER TRUE

2. I feel my quality of life could be better.

TRUE
MOST OFTEN

TRUE
TRUE HALF

THE TIME
ALMOST NEVER TRUE

NEVER TRUE

3. Lifting a child (3 years and under) is something I would not hesitate to do.

TRUE
MOST OFTEN

TRUE
TRUE HALF

THE TIME
ALMOST NEVER TRUE

NEVER TRUE

4. In day-to-day life aches and pains always affect me.

TRUE
TRUE HALF

THE TIME
ALMOST NEVER TRUE

NEVER TRUE

5. I feel confident among people of all ages.

TRUE
MOST OFTEN

TRUE
TRUE HALF

THE TIME
ALMOST
NEVER TRUE

NEVER TRUE

6. If I was stronger I would be more confident with every day activities.

TRUE
MOST OFTEN

TRUE
TRUE HALF
THE TIME
ALMOST NEVER TRUE
NEVER TRUE 
7. I have a positive outlook.

TRUE

$$
\begin{gathered}
\text { MOST OFTEN } \\
\text { TRUE }
\end{gathered}
$$

TRUE HALF

THE TIME
ALMOST NEVER TRUE

NEVER TRUE

8. Ageing has had an impact on my physical well-being.

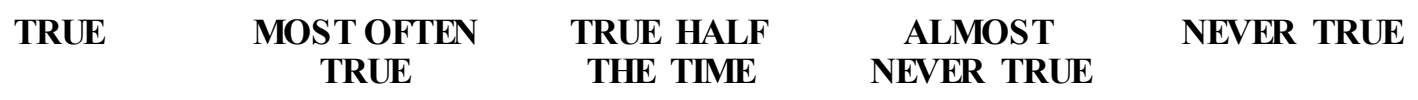

9. Changes in my physical well-being as I age concern me.

TRUE
MOST OFTEN TRUE

\section{TRUE HALF THE TIME}

\section{ALMOST NEVER TRUE}

NEVER TRUE

10. I am satisfied with my present level of health.

TRUE
MOST OFTEN

TRUE
TRUE HALF

THE TIME
ALMOST NEVER TRUE

NEVER TRUE

11. I have no problem with household tasks.

TRUE
MOST OFTEN TRUE
TRUE HALF

THE TIME
ALMOST NEVER TRUE

NEVER TRUE

12. Tasks away from the house (e.g. Shopping) require the assistance of others.

TRUE
TRUE HALF

THE TIME
ALMOST NEVER TRUE

NEVER TRUE TRUE

13. In my garden my activity is not limited.

\section{TRUE}

\section{MOST OFTEN \\ TRUE}

TRUE HALF THE TIME

\section{ALMOST} NEVER TRUE

NEVER TRUE

14. I have trouble getting to sleep.

TRUE MOST OFTEN TRUE
TRUE HALF THE TIME
ALMOST NEVER TRUE

NEVER TRUE

15. My sleep is never broken or restless.

TRUE
MOST OFTEN

TRUE
TRUE HALF
THE TIME
ALMOST NEVER TRUE

NEVER TRUE

16. When I look at my body in the mirror I am satisfied with what I see.

TRUE

\section{MOST OFTEN}

TRUE
TRUE HALF
THE TIME
ALMOST NEVER TRUE
NEVER TRUE 
Appendix F

1. Age:

Demographic and Background Information

2. Gender:

3. Present marital status: (please circle response)
a. Single - never married
b. Married
c. Separated
d. Divorced
e. Widowed
f. Cohabit

4. How many years of education do you presently have (i.e., highest level achieved)? (please circle the corresponding number of years)

$\begin{array}{lcccr}123456 & 789101112 & 13141516 & 17181920 & 2122232425 \\ \text { Elementary } & \text { Secondary } & \text { Undergraduate } & \text { Graduate } & \text { Professional }\end{array}$

5. Which of the following ethnic groups do you most identify with? (please circle response)
a. Caucasian
b. Black
c. Asian
d. Hispanic
e. Other: please specify

6. Which of the following do you most identify with financially? (please circle response)

a. Comfortable, don't worry too much about money

b. Making ends meet, getting by

c. Struggling a lot, have some immediate financial concerns

7. How long have you been participating in this (choir/band/card) activity? Please select and complete the response you feel best describes your length of participation. For example, if you have been participating for 3 months, you would put 3 in front of months below.
a. weeks
b. months
c. ___ years
d. $\_$sessions (e.g., participated in 1 Fall and 1 Winter session $=2$ sessions)
e. occasional drop in dropped in)




\section{WELL-BEING THROUGH SONG}

8. Using the scale below, please rate the degree to which you feel your participation in this (singing/band/cards) program/activity is individuallyoriented, or separate from others doing the activity.

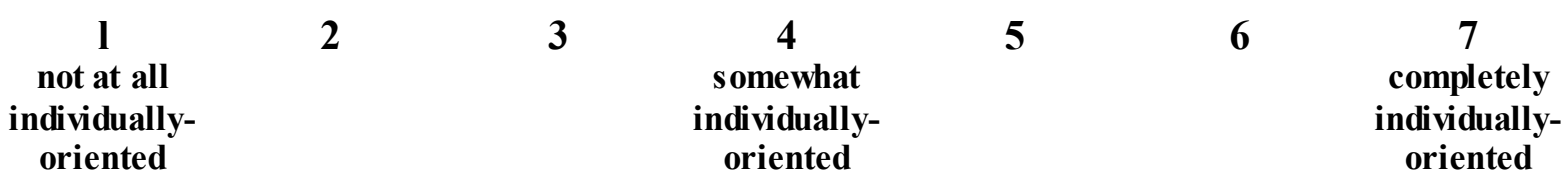

9. Using the scale below, please rate the degree to which you feel your participation in this (singing/band/cards) program/activity is group-oriented.

\begin{tabular}{|c|}
\hline $\begin{array}{c}\text { l } \\
\text { not at all } \\
\text { group- } \\
\text { oriented }\end{array}$ \\
\hline
\end{tabular}

10. Of all of the following reasons, please select the reason that best matches your motivation to join, or start participating in this (choir/band/card) activity in the first place?

a. Making new friends

b. Doing activity with existing friend(s)

c. The nature of the activity itself (e.g., a love for singing/playing instrument/cards)

d. Other (please specify)

11. Of all of the following reasons, please select the reason that best matches your motivation to continue participating in this (choir/band/card) activity? [Please note: If this is only your first session, you should skip this question].

a. Making new friends

b. Doing activity with existing friend(s)

c. The nature of the activity itself (e.g., a love for singing/playing instrument/cards)

d. Other (please specify) 
Appendix G

\section{Leis ure Activities Scale}

We are interested in how often in the last month you were able to spend time in activities that you enjoyed.

Please circle your response according to the following scale. Provide additional activity details where necessary on the line provided. If once a we ek or more, ple as e specify the numbers of hours per week on the line provided.

1. Spending quiet time alone

0 never or do not enjoy
1 once per month
2 once per week a few times per week $\tau_{\text {hours }} \#$ __ $\#$ hours ___ $\#$ hours

4 every day

2. Visiting with others

0 never or do not enjoy
1 once per month
2 once per week -

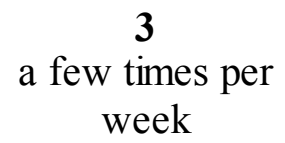
\# hours
4 every day \#

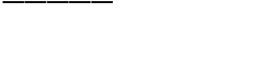

3. Clubs or fraternal organization activities (please specify)

$\begin{array}{ccccc}\mathbf{0} & \mathbf{1} & \mathbf{2} & \mathbf{3} & \mathbf{4} \\ \begin{array}{c}\text { never or do } \\ \text { not enjoy }\end{array} & \begin{array}{c}\text { once per } \\ \text { month }\end{array} & \text { once per week } & \begin{array}{c}\text { a few times per } \\ \text { week }\end{array} & \text { every day } \\ & & - \text { hours }^{*} & \text { \# hours } & \end{array}$

4. Fellowship and religious group participation

0 never or do not enjoy
1 once per month
2 3 once per week \# a few times per week \# hours ___ \# hours 


\section{WELL-BEING THROUGH SONG}

5. Communing with nature

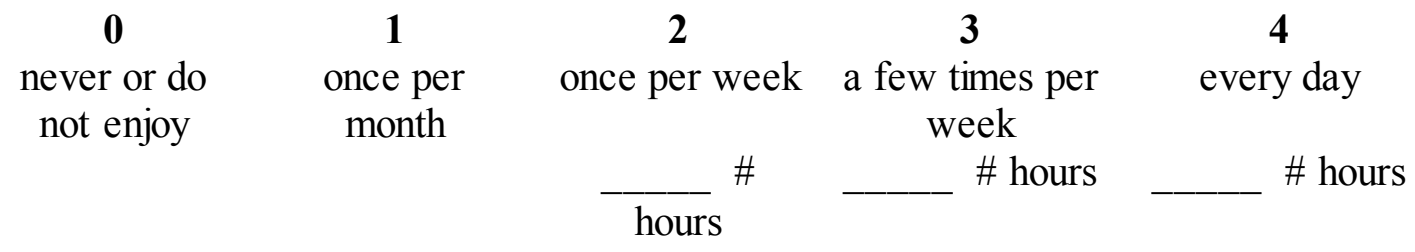

6. Sports and physical activities (please specify)

0 never or do not enjoy
1 once per month
2 once per week hours $\#$

\section{3}

a few times per week
4

every day \# hours ___ \# hours

7. Solo singing

$\mathbf{0}$ never or do not enjoy

\section{1} once per month

\section{2} once per week hours $\#$ 


\section{WELL-BEING THROUGH SONG}

10. Games (e.g., cards, board games, bingo; please specify)

0 never or do not enjoy

\section{2} once per month
23 once per week

a few times per week

$$
\overline{\text { hours }}^{\text {\# }}
$$
\# hours

11. Hobbies (please specify)

$\begin{array}{ccccc}\mathbf{0} & \mathbf{1} & \mathbf{2} & \mathbf{3} & \mathbf{4} \\ \begin{array}{c}\text { never or do } \\ \text { not enjoy }\end{array} & \begin{array}{c}\text { once per } \\ \text { month }\end{array} & \text { once per week } & \begin{array}{c}\text { a few times per } \\ \text { week }\end{array} & \text { every day } \\ & & \text { hours } & & \end{array}$

12. Other (please specify)

0 never or do not enjoy
1 once per month
2 once per week $\overline{\text { hours }}^{\#}$

\section{3}

a few times per week ____ \# hours

4 every day 


\section{WELL-BEING THROUGH SONG}

\section{Appendix $\mathrm{H}$}

\section{The PANAS}

This scale consists of a number of words that describe different feelings and emotions. Read each item and then mark the appropriate answer in the space next to that word. Indicate to what extent you feel this way right now, that is, at the present moment. Use the following scale to record your answers.

\section{1} very slightly or not at all
2 a little interested distressed excited upset strong

$\ldots$ strong
guilty
scared
hostile
enthusiastic
proud

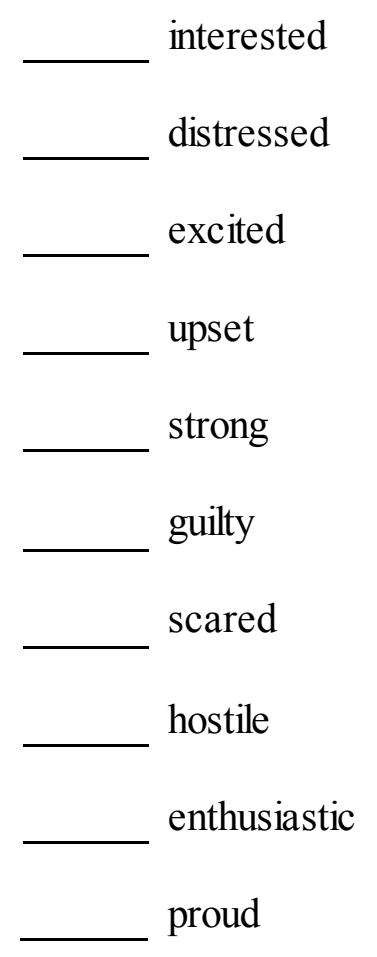

\section{3} mode rately
5 quite a bit extremely 


\section{Appendix I \\ Vitality Scale}

Please respond to each of the following statements by indicating the degree to which the statement is true for you right now.

1. At this moment, I feel alive and vital.

$\begin{array}{cccccc}1 & 2 & 3 & 4 & 5 & 6 \\ \begin{array}{c}\text { not at all } \\ \text { true }\end{array} & & \begin{array}{c}\text { somewhat } \\ \text { true }\end{array} & & & \text { very true }\end{array}$

2. At this moment, I feel so alive I just want to burst.

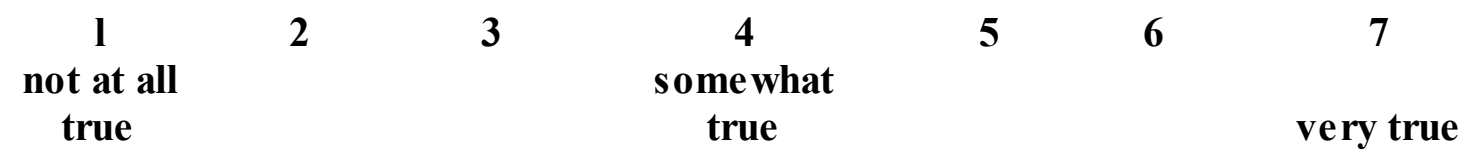

3. At this moment, I have energy and spirit.

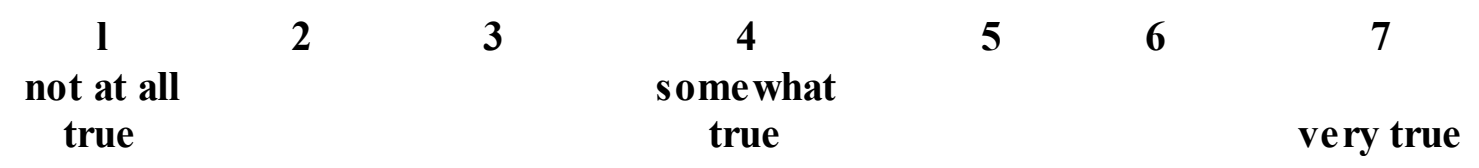

4. At this moment, I look forward to each new day.

$\begin{array}{cccccc}1 & 2 & 3 & 4 & 5 & 6 \\ \begin{array}{c}\text { not at all } \\ \text { true }\end{array} & & \begin{array}{c}\text { somewhat } \\ \text { true }\end{array} & & & \text { very true }\end{array}$

5. At this moment, I feel alert and awake.

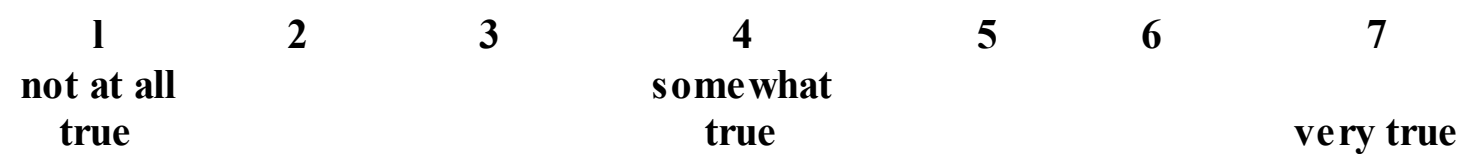

6. At this moment, I feel energized.

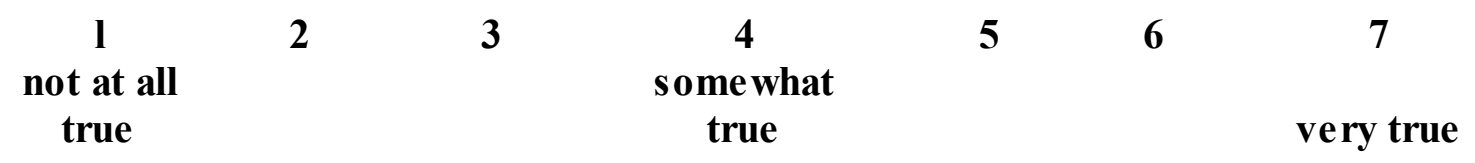


Appendix $\mathbf{J}$

\section{Group Identification Scale}

Think about the [singing group/card group/musical band] in which you participate. Please answer the following questions with respect to that group and your feelings at the present moment.

1. I feel a bond with my [singing group/card group/musical band]

$\begin{array}{ccccccc}\mathbf{1} & \mathbf{2} & \mathbf{3} & \mathbf{4} & \mathbf{5} & \mathbf{6} & \mathbf{7} \\ \begin{array}{c}\text { Strongly } \\ \text { disagree }\end{array} & \text { Disagree } & \begin{array}{c}\text { Slightly } \\ \text { disagree }\end{array} & \begin{array}{c}\text { Neither } \\ \text { agree nor } \\ \text { disagree }\end{array} & \begin{array}{c}\text { Slightly } \\ \text { agree }\end{array} & \text { Agree } & \begin{array}{c}\text { Strongly } \\ \text { agree }\end{array} \\ & & & & & \end{array}$

2. I feel similar to the other members of my [singing group/card group/musical band]

$\begin{array}{ccccccc}\mathbf{1} & \mathbf{2} & \mathbf{3} & \mathbf{4} & \mathbf{5} & \mathbf{6} & \mathbf{7} \\ \begin{array}{c}\text { Strongly } \\ \text { disagree }\end{array} & \text { Disagree } & \begin{array}{c}\text { Slightly } \\ \text { disagree }\end{array} & \begin{array}{c}\text { Neither } \\ \text { agree nor } \\ \text { disagree }\end{array} & \begin{array}{c}\text { Slightly } \\ \text { agree }\end{array} & \text { Agree } & \begin{array}{c}\text { Strongly } \\ \text { agree }\end{array} \\ & & & & & \end{array}$

3. I have a sense of belonging to my [singing group/card group/musical band]

$\begin{array}{ccccccc}\mathbf{1} & \mathbf{2} & \mathbf{3} & \mathbf{4} & \mathbf{5} & \mathbf{6} & \mathbf{7} \\ \begin{array}{c}\text { Strongly } \\ \text { disagree }\end{array} & \text { Disagree } & \begin{array}{c}\text { Slightly } \\ \text { disagree }\end{array} & \begin{array}{c}\text { Neither } \\ \text { agree nor } \\ \text { disagree }\end{array} & \begin{array}{c}\text { Slightly } \\ \text { agree }\end{array} & \text { Agree } & \begin{array}{c}\text { Strongly } \\ \text { agree }\end{array}\end{array}$

4. I have a lot in common with the members of my [singing group/card group/musical band]

$\begin{array}{ccccccc}\mathbf{1} & \mathbf{2} & \mathbf{3} & \mathbf{4} & \mathbf{5} & \mathbf{6} & \mathbf{7} \\ \text { Strongly } & \text { Disagree } & \text { Slightly } & \text { Neither } & \text { Slightly } & \text { Agree } & \text { Strongly } \\ \text { disagree } & & \text { disagree } & \begin{array}{c}\text { agree nor } \\ \text { disagree }\end{array} & \text { agree } & & \text { agree }\end{array}$




\section{Appendix K}

\section{Inclusion of Other in the Self Scale (IOS)}

For this measure you will be asked to select the picture below which best describes your relationship with your (choir/band/card) group by putting a large circle around your selection.
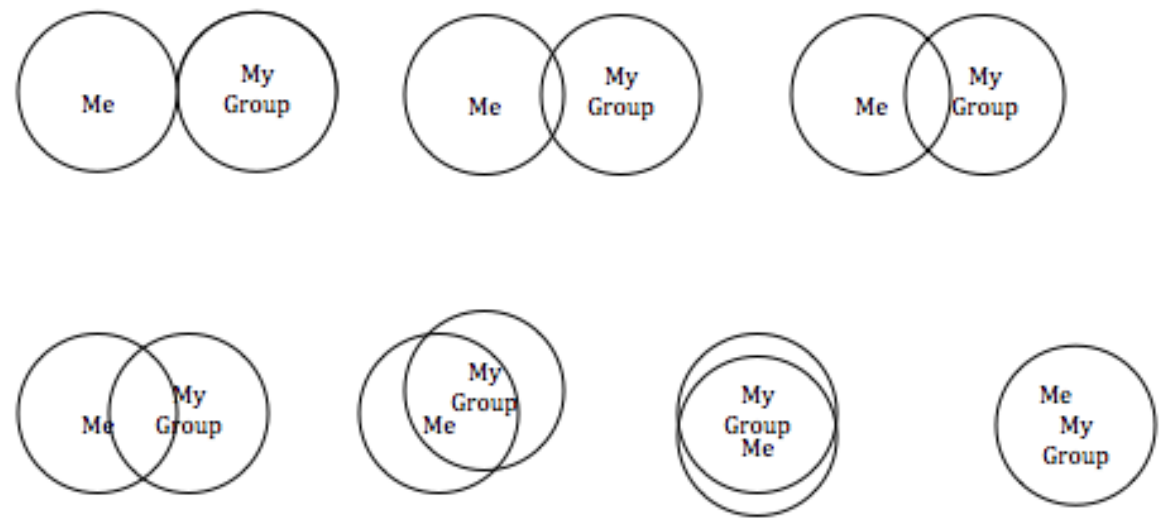

Example 1: If you do not identify at all with your group you would select the 2 separate circles by putting a larger circle around the two separate circles.

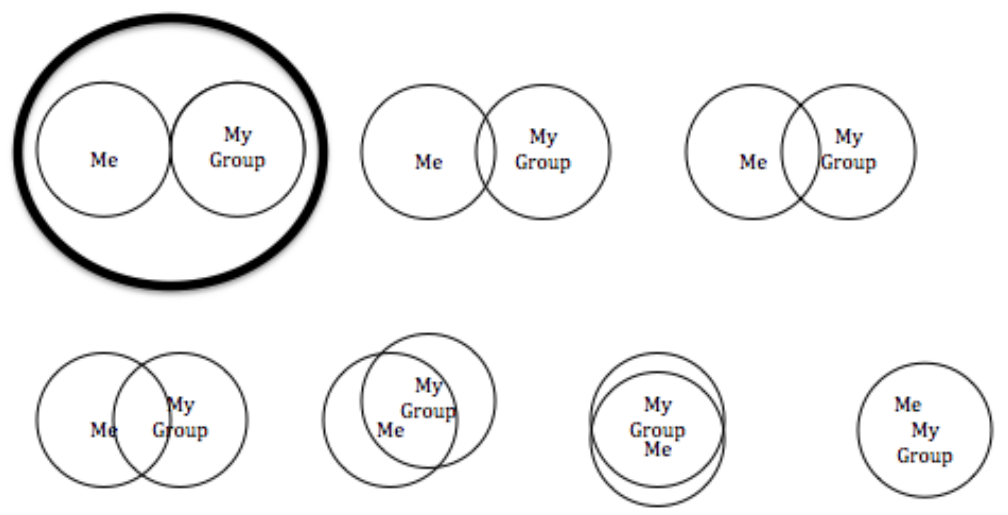

Example 2: If you strongly identify with and feel quite close to your group you might select two circles that overlap very closely, and put a larger circle around them.
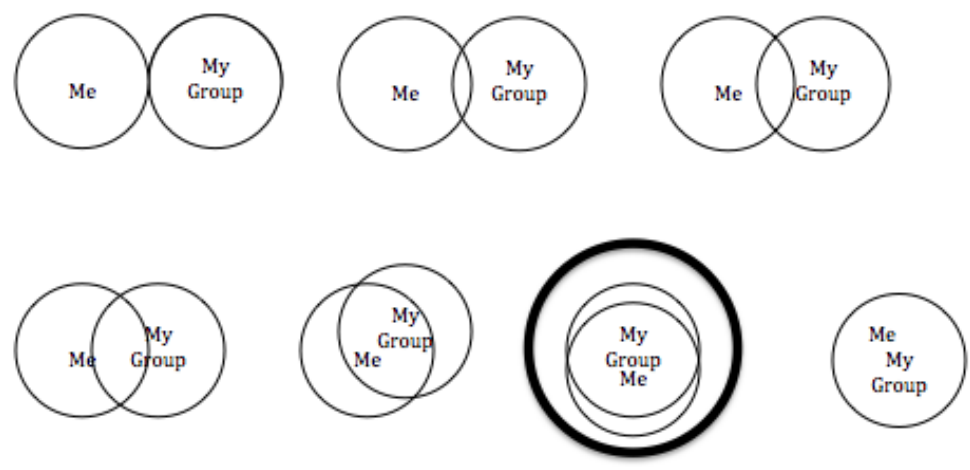


\section{WELL-BEING THROUGH SONG}

Now please circle the picture below which best describes your relationship with your group.

WELL-BEING THROUGH SONG

Appendix L

Pearson Correlations between dependent variables

Bivariate Correlations of all measures

\begin{tabular}{|c|c|c|c|c|c|c|c|c|c|c|c|c|}
\hline & $\begin{array}{c}\text { PA Mean } \\
\text { Before }\end{array}$ & $\begin{array}{c}\text { PA Mean } \\
\text { After }\end{array}$ & $\begin{array}{c}\text { GIS Mean } \\
\text { Before }\end{array}$ & $\begin{array}{c}\text { GIS Mean } \\
\text { After }\end{array}$ & $\begin{array}{c}I O S \\
\text { Before }\end{array}$ & $\begin{array}{l}\text { IOS } \\
\text { After }\end{array}$ & $\begin{array}{c}\text { VS Mean } \\
\text { Before }\end{array}$ & $\begin{array}{c}\text { VS Mean } \\
\text { After }\end{array}$ & $\begin{array}{l}\text { Stress } \\
\text { Before }\end{array}$ & $\begin{array}{l}\text { Stress } \\
\text { After }\end{array}$ & $\begin{array}{c}U Q Q o L \\
\text { Mean }\end{array}$ & $\begin{array}{l}\text { SWLS } \\
\text { Mean }\end{array}$ \\
\hline$\overline{P A M e a n ~ B e f o r e}$ & - & & & & & & & & & & & \\
\hline PA Mean After & $.772^{n \cdots \infty}$ & - & & & & & & & & & & \\
\hline GIS Mean Before & $.320^{m-n}$ & $.297^{\cdots \cdots}$ & - & & & & & & & & & \\
\hline GIS Mean After & $.281^{n \pi}$ & $.244^{\circ}$ & $.649^{\cdots n}$ & - & & & & & & & & \\
\hline IOS Before & $.345^{\ldots \cdots n}$ & .198 & $.471^{n+\infty}$ & $.570^{\cdots \cdots}$ & - & & & & & & & \\
\hline IOS After & $.343^{n \cdots n}$ & $.288^{n \pi}$ & $.421^{n \cdots}$ & $.514^{\cdots \cdots}$ & $.787^{\cdots \cdots n}$ & - & & & & & & \\
\hline VS Mean Before & $.605^{n \cdots n}$ & $.446^{n \pi x}$ & $.367^{n+\infty}$ & $.310^{m-n}$ & $.411^{\cdots \cdots}$ & $.309^{n-\pi}$ & - & & & & & \\
\hline VS Mean After & $.646^{n \cdots n}$ & $743^{r \cdots \infty}$ & $.349^{n \cdots}$ & $350^{\cdots \cdots}$ & .144 & $.226^{\circ}$ & $609^{n \cdots}$ & - & & & & \\
\hline Stress Before & -.011 & .105 & -.186 & -.164 & -.189 & .007 & $-.323^{n \pi}$ & -.102 & - & & & \\
\hline Stress After & -.117 & -.101 & -.116 & $-.339^{n \pi n}$ & -.098 & -.015 & -.177 & $-.241^{\circ}$ & $.505^{\cdots \cdots \pi}$ & - & & \\
\hline UQQoL Mean & $301^{\pi \pi}$ & .192 & .148 & .177 & .118 & .084 & $381^{\cdots \cdots}$ & $406^{\cdots \cdots}$ & $-.456^{n \pi x}$ & $-.377^{n \pi n}$ & - & \\
\hline SWLS Mean & $.339^{n \cdots+}$ & $.210^{\circ}$ & .198 & $.237^{\circ}$ & $360^{\cdots \cdots}$ & .182 & $496^{n+\cdots}$ & $.301^{\pi n}$ & $-.347^{\pi n \pi}$ & $-.251^{\circ}$ & $.374^{\pi \cdots x}$ & - \\
\hline
\end{tabular}

